\title{
PROCEEDINGS OF DRS
}
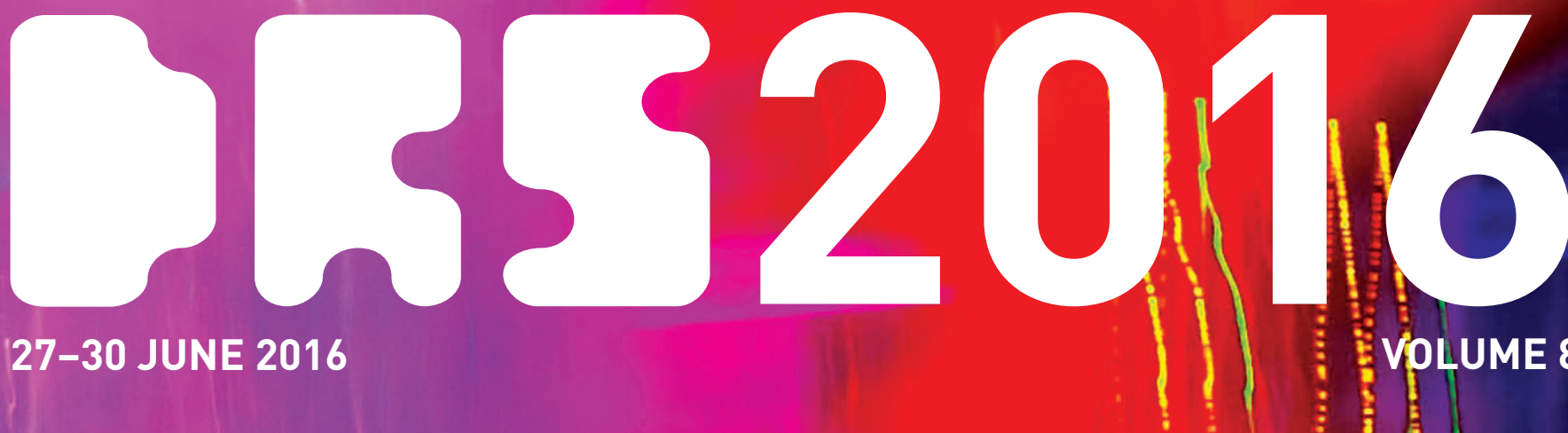

27-30 JUNE 2016

$50^{\text {th }}$ Anniversary Conference Brighton, UK

Design + Research + Society in

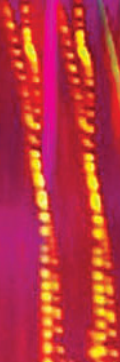

VOLLUME 8

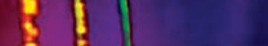




\section{Proceedings of DRS 2016 \\ Design + Research + Society \\ Future-Focused Thinking}

$50^{\text {th }}$ Anniversary International Conference

Brighton, UK, 27-30 June 2016

Volume 8

Editors

Peter Lloyd and Erik Bohemia 


\section{Proceedings of DRS}

2016 International Conference 28-30 June 2016, Brighton, UK www.drs2016.org

Volumes 8 of 10

Cover and conference identity design by Gavin Ambrose, Nikki Brewster and Seamus White Proceedings compiled by Kaajal Modi

Editors: Peter Lloyd and Erik Bohemia

Section-Editors: Harriet Atkinson; Leonard Bachman; Giovanni Baule; Michaël Berghman; Noemi Bitterman; Alison Black; Rebecca Cain; Elena Caratti; Rachel Cooper; Anne Cranny-Francis; Tejas Dhadphale; Hua Dong; Bianca Elzenbaumer; Carolina Escobar-Tello; Luke Feast; Tom Fisher; Aija Freimanee; Lorraine Gamman; Valeria Graziano; Camilla Groth; Marte Gulliksen; Paul Hekkert; Derek Jones; Sarah Kettley; Tore Kristensen; Sylvia Liu; Geke Ludden; Jamie Mackrill; Maarit Mäkelä; Betti Marenko; Andrew Morris; Kristina Niedderer; Nithikul Nimkulrat; Maya Oppenheimer; Elif Ozcan; Verena Paepcke-Hjeltness; Ann Petermans; Philip Plowright; Tiiu Poldma; Hendrik Schifferstein; Pirita Seitamaa-Hakkarainen; Qian Sun; Michael Tovey; Rhoda Trimingham; Kim Trogal; Nynke Tromp; Mieke van der Bijl-Brouwer; Sue Walker; Alex Wilkie; Alex Williams; Seda Yilmaz

(c) (i) This work is licensed under a Creative Commons Attribution-Non Commercial 4.0 International License. http://creativecommons.org/licenses/by-nc/4.0/

\section{Proceedings of DRS 2016 International Conference: Future-Focused Thinking}

\section{ISSN 2398-3132}

Published by the Design Research Society

Loughborough University, London

3 Lesney Avenue, The Broadcast Centre, Here East

London, E15 $2 \mathrm{GZ}$

United Kingdom

Design Research Society Secretariat email: admin@designresearchsociety.org website: www.designresearchsociety.org

Founded in 1966 the Design Research Society (DRS) is a learned society committed to promoting and developing design research. It is the longest established, multi-disciplinary worldwide society for the design research community and aims to promote the study of and research into the process of designing in all its many fields.

DRS Special Interest Groups

Design for Behaviour Change

Design for Health, Wellbeing and Happiness

Design Innovation Management

Design Pedagogy

Design for Sustainability

Design for Tangible, Embedded and Networked Technologies

Experiential Knowledge

Inclusive Design

Objects, Practices, Experiences, Networks

DRS International Conference Series

DRS 2002 London; DRS 2004 Melbourne; DRS 2006 Lisbon; DRS 2008 Sheffield; DRS 2010 Montreal; DRS 2012 Bangkok; DRS 2014 Umeå 


\section{DRS 2016 Programme Committee}

\section{Conference Chair}

Peter Lloyd, University of Brighton, UK

\section{Conference Co-Chairs}

Tracy Bhamra, Loughborough University, United Kingdom Stephen Boyd-Davis, Royal College of Art, United Kingdom Jonathan Chapman, University of Brighton, United Kingdom Peter Childs, Imperial College, United Kingdom

\section{International Scientific Review Committee}

Tracy Bhamra, Loughborough University, United Kingdom Erik Bohemia, Loughborough University, United Kingdom Lin Lin Chen, National Taiwan University of Science and Technology, Taiwan Nathan Crilly, University of Cambridge, United Kingdom Paul Hekkert, TU Delft, The Netherlands Peter Lloyd, University of Brighton, UK

Debates, Conversations and Workshops Chairs Stella Boess, TU Delft, The Netherlands Carlos Peralta, University of Brighton, UK Cameron Tonkinwise, Carnegie Mellon University, US

\section{Conference Experience Chairs}

Dan Lockton, Royal College of Art, UK Veronica Ranner, Royal College of Art, UK

\section{PhD by Design}

Bianca Elzenbaumer, Leeds College of Art, UK

Maria Portugal, Goldsmiths University, UK Alison Thomson, Goldsmiths University, UK

\section{DRS Special Interest Group Chairs}

Erik Bohemia, Loughborough University, UK Rebecca Cain, Warwick University, UK Hua Dong, Tongji University, China Tom Fisher, Nottingham Trent University, UK Sarah Kettley, Nottingham Trent University, UK Kristina Niedderer, University of Wolverhampton, UK Nithikul Nimkulrat, Estonian Academy of Arts, Talinn Michael Tovey, Coventry University, UK Rhoda Trimmingham, Loughborough University, UK

\section{Executive Advisors}

Carl DiSalvo, Georgia Institute of Technology, US Kees Dorst, University of Technology, Sydney, Australia Janet Mcdonnell, University of the Arts London, UK Johan Redström, Umeå Institute of Design, Sweden Erik Stolterman, Indiana University, US

Anna Valtonen, Aalto School of Arts, Design and Architecture, Finland 


\section{International Board of Reviewers}

Tom Ainsworth, University of Brighton, United Kingdom Katerina Alexiou, The Open University, United Kingdom Manola Antonioli, Ecole Nationale Supérieure d'Architecture Paris La Villette, France Rina Arya, Wolverhampton, United Kingdom Harriet Atkinson, University of Brighton, United Kingdom Stephen Awoniyi, Texas State University, United States Jeremy Aynsley, University of Brighton, United Kingdom Leonard Bachman, University of Houston College of Architecture, United States Betsy Barnhart, lowa State University, United States Giovanni Baule, Politecnico di Milano, Italy Nigan Bayazit, Istanbul Technical University, Turkey Michaël Berghman, TU Delft, Netherlands Tracy Bhamra, Loughborough University, United Kingdom Richard Bibb, Loughborough University, United Kingdom Noemi Bitterman, Technion, Israel Alison Black, Reading University, United Kingdom Janneke Blijlevens, Royal Melbourne Institute of Technology University, Australia Anne Boddington, University of Brighton, United Kingdom Stella Boess, Delft University of Technology, Netherlands Erik Bohemia, Loughborough University, United Kingdom Casper Boks, NTNU, Norway Elizabeth Boling, Indiana University, United States Andy Boucher, Goldsmiths, University of London, United Kingdom Simon Bowen, Newcastle University, United Kingdom Stephen Boyd Davis, Royal College of Art, United Kingdom Jamie Brassett, Central Saint Martins, United Kingdom Philip Breedon, Nottingham Trent University, United Kingdom Charlie Breindahl, Royal Danish Academy of Fine Arts, Denmark Patrick Bresnihan, Trinity College Dublin, Ireland Cheryl Buckley, University of Brighton, United Kingdom Jacob Buur, University of Southern Denmark, Denmark Rebecca Cain, University of Warwick, United Kingdom Elena Caratti, Politecnico di Milano, Italy Philip Cash, DTU, Denmark

Tom Cassidy, University of Leeds, United Kingdom Julia Cassim, Kyoto Institute of Technology, Japan Jonathan Chapman, University of Brighton, United Kingdom Chien-Hsiung Chen, Taiwan Tech, Taiwan, R.O.C.

Chun-Chih Chen, National Kaohsiung Normal University, Taiwan, R.O.C. Chun-Di Chen, National Taipei University of Education, Taiwan, R.O.C. Kuohsiang Chen, I-Shou University, Taiwan, R.O.C.

Lin-Lin Chen, National Taiwan University of Science and Technology, Taiwan, R.O.C. Peter Childs, Imperial College London, United Kingdom Wen-Ko Chiou, Chang Gung University, Taiwan, R.O.C. Bo Christensen, Copenhagen Business School, Denmark Henri Christiaans, UNIST, School of Design \& Human Engineering, South Korea Abdusselam Selami Cifter, Mimar Sinan Fine Arts University, Turkey Nazli Cila, Amsterdam University of Applied Sciences, Netherlands Mollie Claypool, University College London, United Kingdom Stephen Clune, Lancaster University, United Kingdom Tim Cooper, Nottingham Trent University, United Kingdom Anne Cranny-Francis, University of Technology Sydney, Australia Nathan Crilly, University of Cambridge, United Kingdom Odette da Silva, TU Delft, Netherlands

Massimo De Angelis, University of East London, United Kingdom Michel de Blois, Université Laval, Canada

Cees de Bont, Hong Kong Polytechnic University, Hong Kong Christine de Lille, Delft University of Technology, Netherlands Jakki Dehn, Jakki Dehn Materials, United Kingdom 
Federico Del Giorgio Solfa, National University of La Plata, Argentina

Claudio Dell'Era, Politecnico di Milano, Italy

Samuel DeMarie, lowa State University, United States

Halime Demirkan, Bilkent University, Turkey

Gaurang Desai, American University of Sharjah, United Arab Emirates

Pieter Desmet, TU Delft, Netherlands

Emma Dewberry, The Open University, United Kingdom

Sarah Diefenbach, Ludwig-Maximilians-Universität München, Germany

Ingvild Digranes, Oslo and Akershus University College of Applied Sciences, Norway

Orsalia Dimitriou, Central Saint Martins, United Kingdom

Hua Dong, Tongji University, China

Dennis Doordan, University of Notre Dame, United States

Kees Dorst, University of Technology Sydney, Australia

Shelby Doyle, lowa State University, United States

Alex Duffy, University of Strathclyde, United Kingdom

Delia Dumitrescu, University of Borås, United Kingdom

Abigail Durrant, Newcastle University, United Kingdom

Thomas Dykes, Northumbria University, United Kingdom

Wouter Eggink, University of Twente, Netherlands

Bianca Elzenbaumer, Leeds College of Art, United Kingdom

Magnus Eneberg, Konstfack - University College of Arts, Crafts and Design, Sweden

Alpay Er, Ozyegin University / Istanbul Institute of Design, Turkey

Ozlem Er, Istanbul Technical University, Turkey

Pia Geisby Erichsen, University of Southern Denmark, Denmark

Carolina Escobar-Tello, Loughborough University, United Kingdom

Juhyun Eune, Seoul National University, South Korea

Mark Evans, Loughborough University, United Kingdom

Luke Feast, Aalto University, Finland

Thomas Fischer, Xi'an Jiaotong-Liverpool University, China

Tom Fisher, Nottingham Trent University, United Kingdom

Kate Tanya Fletcher, London College of Fashion, University of the Arts London, United Kingdom

Jodi Forlizzi, Carnegie Mellon University, United States

Lois Frankel, Carleton University, Canada

Jill Franz, Queensland University of Technology, Australia

Biljana Fredriksen, University College of Southeast Norway, Norway

Ken Friedman, Tongji University, China

Jennifer Gabrys, Goldsmiths, University of London, United Kingdom

Loraine Gamman, Central Saint Martins, University of the Arts, United Kingdom

Nick Gant, University of Brighton, United Kingdom

Philippe Gauthier, Université de Montréal, Canada

Aysar Ghassan, Coventry University, United Kingdom

Katherine Gibson, University of Western Sydney, Australia

Carolina Gill, The Ohio State University, United States

Steve Gill, Cardiff Met University, United Kingdom

Maria Goransdotter, Umeå University, Sweden

Colin Gray, Purdue University, United States

Camilla Groth, Aalto University, School of Arts, Design and Architecture, Finland

Marte Sørebø Gulliksen, Telemark University College, Norway

Ian Gwilt, Sheffield Hallam University, United Kingdom

Robert Harland, Loughborough University, United Kingdom

Dew Harrison, University of Wolverhampton, United Kingdom

Steve Harrison, Virginia Tech, United States

Marc Hassenzahl, Folkwang University of the Arts, Germany

Anders Haug, University of Southern Denmark, Denmark

Tero Heikkinen, independent / University of the Arts Helsinki, Finland

Tincuta Heinzel, Nottingham Trent University, United Kingdom

Paul Hekkert, Delft University of Technology, Netherlands

Bart Hengeveld, Technische Universiteit Eindhoven, Netherlands

Ricardo Hernandez, Lancaster University, United Kingdom

Ann Heylighen, KU Leuven, Belgium

Clive Hilton, Coventry University, United Kingdom 
Michael Hohl, Anhalt University of Applied Sciences, Germany Chung-Ching Huang, National Taiwan University, Taiwan, R.O.C.

Karl Hurn, Loughborough University, United Kingdom

Praima Israsena Na Ayudhya, Chulalongkorn University, Thailand

Robert Jerrard, Manchester Metropolitan Univ/Birmingham City Univ, United Kingdom

Wolfgang Jonas, Braunschweig University of Art, Germany

Derek Jones, The Open University, United Kingdom

Peter Jones, OCAD University, Canada

Rachel Jones, Instrata, United Kingdom

Guy Julier, University of Brighton/Victoria and Albert Museum, United Kingdom

Sabine Junginger, Hertie School of Governance, Germany

Lorraine Justice, Rochester Institute of Technology, United States

Faith Kane, Loughborough University, United Kingdom

Helen Kennedy, University of Brighton, United Kingdom

Tobie Kerridge, Goldsmiths, University of London, United Kingdom

Richard Arthur Kettley, Nottingham Trent University, United Kingdom

Sarah Kettley, Nottingham Trent University, United Kingdom

Jinsook Kim, Trinity Christian College, United States

Lucy Kimbell, UAL, United Kingdom

Holger Klapperich, Folkwang University of Arts, Germany

Maaike Kleinsmann, TU Delft, Netherlands

Ben Kraal, Queensland University of Technology, Australia

Ksenija Kuzmina, Loughborough University London, United Kingdom

John Langrish, Salford University, United Kingdom

Keelin Leahy, University of Limerick, Ireland

Helmut Leder, University of Vienna, Austria

Ji-Hyun Lee, KAIST, South Korea

Yanki Lee, Hong Kong Design Institue, Hong Kong

Eva Lenz, Folkwang University of Arts, Germany

Pierre Levy, Eindhoven University of Technology, Netherlands

Debra Lilley, Loughborough University, United Kingdom

Rungtai Lin, National Taiwan University of Arts, Taiwan, R.O.C.

Stephen Little, Asia Pacific Technology Network, United Kingdom

Sylvia Liu, Hong Kong Polytechnic University, Hong Kong

Peter Lloyd, University of Brighton, United Kingdom

Kathy Pui Ying, Lo, Loughborough University, United Kingdom

Dan Lockton, Royal College of Art, United Kingdom

Vicky Lofthouse, Loughborough University, United Kingdom

Lian Loke, University of Sydney, Australia

Nicole Lotz, The Open University, United Kingdom

Rachael Luck, The Open University, United Kingdom

Geke Ludden, University of Twente, Netherlands

Rohan Lulham, University of Technology Sydney, Australia

Ole Lund, Norwegian University of Science and Technology, Norway

Alastair Macdonald, Glasgow School of Art, United Kingdom

Fiona Maciver, Norwich University of the Arts, United Kingdom

Jamie Mackrill, Imperial College London, United Kingdom

Anja Maier, Technical University of Denmark, Denmark

Maarit Mäkelä, Aalto University, Finland

Betti Marenko, Central Saint Martins, University of the Arts London, United Kingdom

Ben Mathews, The University of Queensland, Australia

Tuuli Mattelmäki, Aalto University, Finland

Ramia Mazé, Aalto University, Finland

Sanjoy Mazumdar, University of California, Irvine, United States

Janet McDonnell, Central Saint Martins, University of the Arts London, United Kingdom

Chris McGinley, Royal College of Art, United Kingdom

Tomislav Medak, Multimedia Institute, Croatia

Wellington Gomes de Medeiros, Federal University of Campina Grande, Brazil

Brian Mennecke, lowa State University, United States

Paul Micklethwaite, Kingston University, United Kingdom

Karen Miller, University of Brighton, United Kingdom 
Val Mitchell, Loughborough University, United Kingdom Kathryn Moore, Birmingham City University, United Kingdom

Michael Moore, Ulster University, United Kingdom

Sarah Morehead, Northumbria University, United Kingdom

Nicola Morelli, Aalborg University, Denmark

Mariale Moreno, Cranfield University, United Kingdom

Andrew Morris, Loughborough University, United Kingdom

Andrew, Morrison, AHO, Norway

Jeanne-Louise Moys, Reading University, United Kingdom

Tara Mullaney, Umeå Institute of Design, Sweden

Yukari Nagai, Japan Advanced Institute of Science and Technology, Japan

Ki Young Nam, KAIST, South Korea

Kristina Niedderer, Wolverhampton University, United Kingdom

Liv Merete Nielsen, Oslo and Akershus university college, Norway

Nithikul Nimkulrat, Estonian Academy of Arts, Estonia

Conall Ó Catháin, Past Chairman DRS, Ireland

Arlene Oak, University of Alberta, Canada

Maya Oppenheimer, Royal College of Art, United Kingdom

Elif Ozcan, Delft University of Technology, Netherlands

Kursat Ozenc, Stanford, United States

Verena Paepcke-Hjeltness, lowa State University, United States

Eujin Pei, Brunel University London, United Kingdom

Carlos Peralta, University of brighton, United Kingdom

José Pérez de Lama, University of Sevilla, Spain

Oscar Person, Aalto University, Finland

Ann Petermans, Hasselt University, Belgium

Daniela Petrelli, Sheffield Hallam University, United Kingdom

Doina Petrescu, The University of Sheffield, United Kingdom

Ida Nilstad Pettersen, Norwegian University of Science and Technology (NTNU), Norway

Sarah Pink, RMIT University, Australia

Silvia Pizzocaro, Politecnico di Milano, Italy

Philip Plowright, Lawrence Technological University, Universidad de Castilla-La Mancha, United States

Anna Pohlmeyer, Delft University of Technology, Netherlands

Tiiu Poldma, University of Montreal, Canada

Lubomir Popov, Bowling Green State University, United States

Vesna Popovic, Queensland University of Technology, Australia

Thomas Porathe, Norwegian University of Science and Technology, Norway

Ruben Post, TU Delft, Netherlands

William Prindle, lowa State University, United States

Charlie Ranscombe, Swinburne, Australia

Yaone Rapitsenyane, University of Botswana, Botswana

Ingo Rauth, Chalmers University of Technology, Sweden

Kirstine Riis, University College Telemark, Norway

Paul Rodgers, Northumbria University, United Kingdom

Zoe Romano, WeMake, Makerspace, Italy

Jose Antonio Rosa, lowa State University, United States

Seymour Roworth-Stokes, Coventry University, United Kingdom

Robin Roy, The Open University, United Kingdom

Keith Russell, University of Newcastle, Australia, Australia

Daniel Saakes, KAIST, South Korea

Noemi Maria Sadowska, Regent's University London, United Kingdom

Miguel Said Vieira, Independent, Brazil

Fatina Saikaly, Co-Creando, Italy

Filippo Salustri, Ryerson University, Canada

Liz Sanders, The Ohio State University, United States

Rick Schifferstein, TU Delft, Netherlands

James Self, UNIST, South Korea

Nick Senske, lowa State University, United States

Matt Sinclair, Loughborough University, United Kingdom

Kin Wai Michael Siu, The Hong Kong Polytechnic University, Hong Kong

Dirk Snelders, TU Delft, Netherlands 
Ricardo Sosa, Auckland University of Technology, New Zealand

Chris Speed, University of Edinburgh, United Kingdom

Jak Spencer, The Sound HQ, United Kingdom

Kay Stables, Goldsmiths, University of London, United Kingdom

Pieter Jan Stappers, Delft University of Technology, Netherlands

Shanti Sumartojo, RMIT University, Australia

Kärt Summatavet, Aalto University, Estonia

Qian Sun, Royal College of Art, United Kingdom

Helena Sustar, Aalto University, Finland

Gunnar Swanson, East Carolina University, United States

Ben Sweeting, University of Brighton, United Kingdom

Keith Tam, University of Reading, United Kingdom

Hsien-Hui Tang, National Taiwan University of Science and Technology, Taiwan, R.O.C.

Toshiharu Taura, Kobe University, Japan

Damon Taylor, University of Brighton, United Kingdom

Sarah Teasley, Royal College of Art, United Kingdom

Adam Thorpe, University of the Arts London, United Kingdom

Clementine Thurgood, University of Technology Sydney, Australia

Jeremy Till, Central Saint Martins, University of the Arts London, United Kingdom

Oscar Tomico, Eindhoven University of Technology, United Kingdom

Cameron Tonkinwise, Carnegie Mellon University, United States

Mike Tovey, Coventry University, United Kingdom

Rhoda Trimingham, Loughborough University, United Kingdom

Nynke Tromp, TU Delft, Netherlands

Darren Umney, Open University, United Kingdom

Louise Valentine, University of Dundee, United Kingdom

Anna Valtonen, Aalto University, Finland

Mieke van der Bijl-Brouwer, University of Technology Sydney, Australia

Johann van der Merwe, Independent Researcher, South Africa

Mascha van der Voort, University of Twente, Netherlands

Karel van der Waarde, Graphic Design - Research, Belgium

Susann Vihma, Aalto University, Finland

Andre Viljoen, University of Brighton, United Kingdom

John Vines, Newcastle University, United Kingdom

Bettina von Stamm, Innovation Leadership Forum, United Kingdom

Sue Walker, Reading University, United Kingdom

Renee Wever, Linköping University, Sweden

Alex Wilkie, Goldsmiths, University of London, United Kingdom

Alex Williams, Kingston University, United Kingdom

Garrath Wilson, Loughborough University, United Kingdom

Heather Wiltse, Umeå University, Sweden

Christian Woelfel, TU Dresden, Germany

Martin Woolley, Coventry University, United Kingdom

Paul Wormald, National University of Singapore, Singapore

Artemis Yagou, Macromedia University for Media and Communication, Germany

Joyce Yee, Northumbria University, United Kingdom

Susan Yelavich, The New School, United States

Seda Yilmaz, lowa State University, United States

Robert Young, Northumbria University, United Kingdom 


\section{Table of Content}

- Volume 1 -

SECTION 1

50 YEARS OF DESIGN RESEARCH

Design Research: What is it? What is it for?

Victor Margolin

Schön's Legacy: Examining Contemporary Citation Practices in DRS Publications.

Jordan Beck, Laureline Chiapello

The Idea of Architecture, The User As Inhabitant: Design through a Christopher Alexander Lens ................................................... 31

Molly Wright Steenson

Design Research for Sustainability: Historic Origin and Development

Astrid Skjerven

The Design Methods Movement: From Optimism to Darwinism.

John Z. Langrish

User Design: Constructions of the "user" in the history of design research

Theodora Vardouli

60 years of creativity in business organizations.

Ricardo Sosa, Pete Rive and Andy M. Connor

20th Century Boys: Pioneering British Design Thinkers

Emma Murphy and Martyn Evans

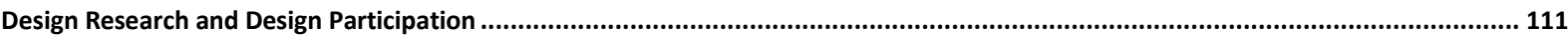

Robert Aish

The Design Research Society in the 1980s and 1990s: a memoir

Conall Ó Catháin

SECTION 2

AESTHETIC PLEASURE IN DESIGN

Introduction: Aesthetic Pleasure in Design

Michaël Berghman and Paul Hekkert

Measuring design typicality - a comparison of objective and subjective approaches

Stefan Mayer and Jan R. Landwehr

Most Advanced yet Acceptable: A case of referential form-driven meaning innovation

Seong geun Lee, James Self and Ekaterina Andrietc

Extracting Design Aesthetic Heuristics from Scientific Literature.

Ana Cadavid, Stefany Ruiz-Córdoba and Jorge Maya

Putting product design in context: Consumer responses to design fluency as a function of presentation context

Laura K. M. Graf and Jan R. Landwehr

The Value of Transparency for Designing Product Innovations.

Peiyao Cheng and Ruth Mugge

A comparison between colour preference and colour harmony - taking athletic shoe design as an example.

Li-Chen $\mathrm{Ou}$

Creating Novel Encounters with Nature: Approaches and Design Explorations.

Thomas J. L. Van Rompay and Geke D. S. Ludden

Introducing Experience Goals into Packaging Design .....

Markus Joutsela and Virpi Roto

The beauty of balance - An empirical integration of the Unified Model of Aesthetics for product design

Michaël Berghman and Paul Hekkert

\section{SECTION 3}

DESIGN EPISTEMOLOGY

Introduction: Design Epistemology.

Derek Jones, Philip Plowright, Leonard Bachman and Tiiu Poldma

Mapping design knowledge: 36 years of Design Studies

Kathryn Burns, Jack Ingram and Louise Annable

I know this one, but the answer is complex.

Simon Downs

Source domains of Architectural Knowledge: Mappings, Categories, Validity and Relevance

Philip D Plowright

Using Rhetoric in Persuasive Design: What Rhetoric?

Danny Godin

Design Fiction: Does the search for plausibility lead to deception?

Paul Coulton, Joseph Lindley and Haider Ali Akmal 
Introduction: Design Education and Learning

"Dis-course is Killer!" Educating the critically reflective designer

Veronika Kelly

Design Culture and Contemporary Education

Therese Uri

Promoting an emancipatory research paradigm in Design Education and Practice...

Design Thinking: A Rod For Design's Own Back?

Aysar Ghassan

Designing the unknown: supervising design students who manage mental health issues

Welby Ings

Using Design Thinking to create a new education paradigm for elementary level children for higher student engagement and success 501 Lesley-Ann Noel and Tsai Lu Liu

Design Research in Interior Design Education: A Living Framework for Teaching the Undergraduate Capstone Studio in the $21^{\text {st }}$ Century

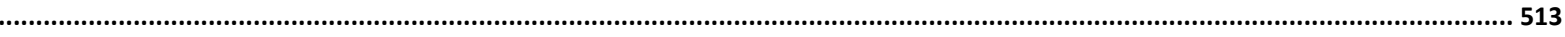

Charles Boggs, Helena Moussatche, Catherine Pizzichemi and Meghan Woodcock

Designing Universities of the Future.

Anna Valtonen

Dexign Futures: A Pedagogy for Long-Horizon Design Scenarios

Peter Scupelli, Arnold Wasserman, and Judy Brooks

Design and Interdisciplinarity: the improbable introduction of "fundamental physics" in a design school

Annie Gentes, Anne-Lyse Renon and Julien Bobroff

Card Games Creation as a Learning Method

Birgit S. Bauer

"Spend another day in our class talking about this research please": Student insights from a research-based design thinking exercise 593

Cynthia J. Atman, Arif Ahmer, Jennifer A. Turns and Jim Borgford-Parnell

Communication is not collaboration: observations from a case study in collaborative learning. 609

lestyn Jowers, Mark Gaved, Gary Elliott-Cirigottis, Delphine Dallison, Alan Rochead and Mark Craig

The use of argumentation in design research .

Stella Boess

Digital Sketch Modelling: Integrating digital sketching as a transition between sketching and CAD in Industrial Design Education ....... 637

Charlie Ranscombe and Katherine Bissett-Johnson

Prototyping in the in-between. A Method for Spatial Design education

Jennie Andersson Schaeffer and Marianne Palmgren

Global Flows of Materials: Design Research and Practice in Architecture.

Janet McGaw

Evaluating Living and Learning on Campus: A Community Engaged Research Model...

Rebekah Radtke

What is sought from graphic designers? A first thematic analysis of job offers for graphic design positions in the United Kingdom ...... 705

Paulo Roberto Nicoletti Dziobczenskiand Oscar Person

LIVD: An Avant-Garde Publication with Pedagogical and Epistemological Aims.

Meredith James

Design Studio Desk and Shared Place Attachments: A Study on Ownership, Personalization, and Agency.

Peter Scupelli and Bruce Hanington

Online Reflective Interactions on Social Network Sites in Design Studio Course

Simge Hough

Junior designers' awareness of personal values and their employment choices

Anna Jonkmans, Julia Wurl, Dirk Snelders and Lenny van Onselen

Knowledgeability culture: Co-creation in practice.

Alicen Coddington, Colin Giang, Alexander Graham, Anne Prince, Pauliina Mattila, Christine Thong and Anita Kocsis

Visual Thinking Styles and Idea Generation Strategies Employed in Visual Brainstorming Sessions

Naz A.G.Z. Börekçi

The Future of Product Design Utilising Printed Electronics

Nicola York, Darren Southee and Mark Evans 
Project Contribution of Junior Designers: Exploring the What and the How of Values in Collaborative Practice

Lennart Kaland, Annelijn Vernooij and Lenny van Onselen

Exploring framing within a team of industrial design students.

Mithra Zahedi, Lorna Heaton, Manon Guité, Giovanni De Paoli and Marie Reumont

\section{- Volume 3 -}

SECTION 5

AESTHETICS, COSMOPOLITICS AND DESIGN

Introduction: Aesthetics, Cosmopolitics and Design

Alex Wilkie

Framing Values in Design

Marta Gasparin and William Green

The Prototype as a Cosmopolitical Place: Ethnographic design practice and research at the National Zoo.

Martín Tironi, Pablo Hermansen and José Neira

The Role of Participation in Designing for loT.

Anuradha Reddy and Per Linde

Aesthetics, Cosmopolitics and Design Futures in Computational Fashion.

Laura Forlano

Designing diagrams for social issues

Michele Mauri and Paolo Ciuccarelli

iPhoneography and New Aesthetics: The Emergence of a Social Visual Communication Through Image-based Social Media

Eman Alshawaf

A Creative Ontological Analysis of Collective Imagery during Co-Design for Service Innovation...

Priscilla Chueng-Nainby, John Lee, BingXin Zi and Astury Gardin

Post-critical potentials in experimental co-design.

Sissel Olander

Collaborative Imaging. The communicative practice of hand sketching in experimental physics

Judith Marlen Dobler

The Aesthetics of Action in New Social Design

Ilpo Koskinen

Designing Debate: The Entanglement of Speculative Design and Upstream Engagement

Tobie Kerridge

\section{SECTION 6}

DESIGN AND TRANSLATION

Introduction: Design and Translation

Giovanni Baule and Elena Caratti

Towards Translation Design A New Paradigm for Design Research

Giovanni Baule and Elena Caratti

Design as translation activity: a semiotic overview.....

Salvatore Zingale

Word to Image - Image to Word The Contribution of Visual Communication to Understanding and Dialog

Michael Renner

Perception, Meaning and Transmodal Design.

Mathias Nordvall and Mattias Arvola

The Ways of Synesthetic Translation: Design models for media accessibility.

Dina Riccò

The narratives and the supports. Remediating Design Culture in the translation of transmedia artefacts.

Matteo Ciastellardi and Derrick de Kerckhove

Rules of Thumb: An Experiment in Contextual Transposition

Damon Taylor, Monika Büscher, Lesley Murray, Chris Speed and Theodore Zamenopoulos

Juxtaposing Chinese and Western Representational Principles: New Design Methods for Information Graphics in the Field of

Intercultural Communication .

Ruedi Baur and Ulrike Felsing

Elucidating perceptions of Australian and Chinese industrial design from the next generation of industrial designers

Blair Kuys and Wenwen Zhang

Translating picturebooks: Re-examining interlingual and intersemiotic translation

Anne Ketola

Long Kesh: Site - Sign - Body.

Ola Ståhl 
SECTION 7

DESIGN FOR DESIGN - THE INFLUENCE AND LEGACY OF JOHN HESKETT

Introduction: Design for Design The Influence and Legacy of John Heskett

Tore Kristensen and Sylvia Liu

Doing qualitative studies, using statistical reasoning

Gorm Gabrielse and Tore Kristensen

Design as Driver for Understanding Sustainability and Creating Value in the Fur Industry

Irene Alma Lønne, Else Skjold

Design Awareness: Developing Design Capacity in Chinese Manufacturing Industry ....

Sylvia Liu

Design Expanding into Strategy: Evidence from Design Consulting Firms

Suzan Boztepe

- Volume 4 -

SECTION 8

Design for Behaviour Change

Introduction: Design for Behaviour Change

Kristina Niedderer, Geke Ludden, Rebecca Cain, Andrew Morris and Aija Freimane

An alternative approach to influencing behaviour: Adapting Darnton's Nine Principles framework for scaling up individual upcycling 1277 Kyungeun Sung, Tim Cooper and Sarah Kettley

Assessment of the Co-creative Design Process .

Pratik Vyas, Robert Young, Petia Sice and Nicholas Spencer

The potential of Design for Behaviour Change to foster the transition to a circular economy

Laura Piscicelli and Geke Dina Simone Ludden

Developing a theory-driven method to design for behaviour change: two case studies

Anita Van Essen, Sander Hermsen and Reint Jan Renes

What a designer can change: a proposal for a categorisation of artefact-related aspects

Anneli Selvefors, Helena Strömberg and Sara Renström

Exploring and communicating user diversity for behavioural change

Aykut Coskun and Cigdem Erbug

How I learned to appreciate our tame social scientist: experiences in integrating design research and the behavioural sciences..........1375

Sander Hermsen, Remko van der Lugt, Sander Mulder and Reint Jan Renes

A Design Approach for Risk Communication, the Case of Type 2 Diabetes..

Farzaneh Eftekhari and Tsai Lu Liu

Metadesigning Design Research - How can designers collaboratively grow a research platform?

Mathilda Tham, Anna-Karin Arvidsson, Mikael Blomqvist, Susanne Bonja, Sara Hyltén-Cavallius, Lena Håkansson, Miguel

Salinas, Marie Sterte, Ola Ståhl, Tobias Svensén and Ole Victor

SECTION 9

Design for Health, Wellbeing and Happiness

Introduction: Design for Health, Wellbeing and Happiness

Rebecca Cain, Noemi Bitterman, Geke Ludden, Jamie Mackrill, Elif Ozcan, Ann Petermans and Carolina Escobar-Tello

In the moment: designing for late stage dementia.

Cathy Treadaway, David Prytherch, Gail Kenning and Jac Fennell

Design for Ageing-in-place: Evidence from Australia

Naseem Ahmadpour and Alen Keirnan

Supporting healthy behaviour: A stages of change perspective on changing snacking habits of children

Geke D.S. Ludden and Laura H.J. de Ruijter

Co-creating narratives: an approach to the design of interactive medical devices, informed by phenomenology.

Rowan Page and Mark Richardson

A Design Primer for the Domestication of Health Technologies

Paul Chamberlain and Claire Craig

Disentangling complexity: a visualisation-led tool for healthcare associated infection training

Alastair S. Macdonald, David Loudon, Susan Wan and Colin Macduff

Exploring Design for Happiness in the Home and Implications for Future Domestic Living

Emily Corrigan-Doyle, Carolina Escobar-Tello and Kathy Pui Ying Lo

Using symbolic meaning as a means to design for happiness: The development of a card set for designers

Mafalda Casais, Ruth Mugge and Pieter M. A. Desmet

Designs with benefits: hearth fire nights and bittersweet chores

Stella U. Boess and Anna E. Pohlmeyer

Happy moments: A well-being driven design of a Car2Go.

Tessa Duste, Pieter Desmet and Elmer van Grondelle 
Games as Speculative Design: Allowing Players to Consider Alternate Presents and Plausible Futures

Paul Coulton, Dan Burnett and Adrian Gradinar

An approach to future-oriented technology design - with a reflection on the role of the artefact.

Tiina Kymäläinen

Future Product Ecosystems: discovering the value of connections

Tim Williams and Marianella Chamorro-Koc

Vision Concepts within the landscape of design research

Ricardo Mejia Sarmiento, Gert Pasman and Pieter Jan Stappers

Visual conversations on urban futures. Participatory methods to design scenarios of liveable cities

Serena Pollastri, Rachel Cooper, Nick Dunn and Chris Boyko

- Volume 5 -

SECTION 11

Design Innovation Management

Introduction: Design Innovation Management

Rachel Cooper, Alex Williams, Qian Sun and Erik Bohemia

Emerging Trends of Design Policy in the UK

Qian Sun

Resourcing in Co-Design

Salu Ylirisku, Jacob Buur and Line Revsbæk

From Participation to Collaboration: Reflections on the co-creation of innovative business ideas

Cara Broadley, Katherine Champion, Michael Pierre Johnson and Lynn-Sayers McHattie

Bridging service design with integrated co-design decision maker interventions.

Sune Gudiksen, Anders Christensen and Pernille Henriksen

Exploring framing and meaning making over the design innovation process

Clementine Thurgood and Rohan Lulham

The making of sustainable cultural and creative cluster in Hong Kong

Kaman Ka Man Tsang and Kin Wai Michael Siu

An exploration of Service Design Jam and its ability to foster Social Enterprise...............................................................................1811

Ksenija Kuzmina, Chris Parker, Gyuchan Thomas Jun, Martin Maguire, Val Mitchell, Mariale Moreno and Samantha Porter

Fiction as a resource in participatory design

Eva Knutz, Tau U. Lenskjold and Thomas Markussen

Space as organisational strategy

Pia Storvang

The value of design: an issue of vision, creativity and interpretation

Mariana Fonseca Braga

A Multilevel Approach to Research 'Obscure' Innovation Processes and Practices

Emmanouil Chatzakis, Neil Smith and Erik Bohemia

Coordinating product design with production and consumption processes

Anders Haug

How Companies adopt different Design approaches.

KwanMyung Kim

Challenges in co-designing a building .

Min Hi Chun

SECTION 12

\section{DESIGN PROCESS}

Form as an abstraction of mechanism

Lewis Urquhart and Andrew Wodehouse

Integrating Nanotechnology in the Design Process: An Ethnographic Study in Architectural Practice in Egypt

Ramy Bakir and Sherif Abdelmohsen

Of Open bodies: Challenges and Perspectives of an Open Design Paradigm.

Émeline Brulé and Frédéric Valentin

Provocative design for unprovocative designers: Strategies for triggering personal dilemmas

Deger Ozkaramanli and Pieter M. A. Desmet

A case based discussion on the role of Design Competences in Social Innovation

Tamami Komatsu, Manuela Celi, Francesca Rizzo and Alessandro Deserti

Riding Shotgun in the Fight Against Human Trafficking.

Lisa Mercer

Could LEGO ${ }^{\circledR}$ Serious Play $^{\circledR}$ be a useful technique for product co-design?

Julia Anne Garde and Mascha Cecile van der Voort 
Intuitive Interaction research - new directions and possible responses.

Alethea Blackler and Vesna Popovic

Skilling and learning through digital Do-It-Yourself: the role of (Co-)Design

Giuseppe Salvia, Carmen Bruno and Marita Canina

Design Research, Storytelling, and Entrepreneur Women in Rural Costa Rica: a case study

Maria Gabriela Hernandez

Temporal design: looking at time as social coordination.

Larissa Pschetz, Michelle Bastian and Chris Speed

A Physical Modeling Tool to Support Collaborative Interpretation of Conversations.

Piotr Michura, Stan Ruecker, Celso Scaletsky, Guilherme Meyer, Chiara Del Gaudio, Gerry Derksen, Julia Dias, Elizabeth

Jernegan, Juan de la Rosa, Xinyue Zhou and Priscilla Ferronato

- Volume 6-

SECTION 13

DESIGN INNOVATION FOR SOCIETY

Introduction: Design Innovation for Society

Nynke Tromp and Mieke van der Bijl-Brouwer

The Challenges of Human-Centred Design in a Public Sector Innovation Context

Mieke van der Bijl-Brouwer

Activating the core economy by design ....

Rebeca Torres Castanedo and Paul Micklethwaite

On presenting a rich picture for stakeholder dialogue

Abigail C. Durrant, Wendy Moncur, David S. Kirk, Diego Trujillo Pisanty and Kathryn Orzech

Design and the Creation of Representational Artefacts for Interactive Social Problem Solving ......

Richard Cooney, Nifeli Stewart, Tania Ivanka and Neal Haslem

Appreciative Co-design: From Problem Solving to Strength-Based Re-authoring in Social Design

Tasman Munro

Design Tools for Enhanced New Product Development in Low Income Economies ....

Timothy Whitehead, Mark Evans and Guy Bingham

Redesigning governance - a call for design across three orders of governance.

Tanja Rosenqvist and Cynthia Mitchell

Involving stakeholders in cross-border regional design.

Annet Kempenaar

From the specificity of the project in design to social innovation by design: a contribution

Marie-Julie Catoir-Brisson, Stéphane Vial, Michela Deni and Thomas Watkin

\section{SECTION 14}

EFFECTIVE INFORMATION DESIGN

Introduction: Effective Information Design..

Alison Black and Sue Walker

Informing the design of mobile device-based patient instructions leaflets: the case of Fentanyl patches

Myrto Koumoundourou, Panayiotis Koutsabasis and Jenny S. Darzentas

Design methods for meaning discovery: a patient-oriented health research case study

David Craib and Lorenzo Imbesi

Expectations and prejudices usurp judgements of schematic map effectiveness.

Maxwell J. Roberts and Ida C.N. Vaeng

Data Visualisation Does Political Things

Joanna Boehnert

The information designer through the lens of design for learning.

Eden Potter

A user centred approach to developing an actionable visualisation for 'balance health'

Shruti Grover, Simon Johnson, Ross Atkin and Chris Mcginley

SECTION 15

Design Thinking

Introduction: Design Thinking

Seda Yilmaz, Verena Paepcke-Hjeltness and Tejas Dhadphale

From Technology-Driven to Experience-Driven Innovation: A Case from the Aviation Industry using VIP

Wan-Jen Jenny Tsay and Christine de Lille

Critically Exploring the Development of a Conceptual Framework for Building Innovative Brands.

Xinya You and David Hands

United We Stand: A Critique of the Design Thinking Approach in Interdisciplinary Innovation

Fiona Maciver, Julian Malins, Julia Kantorovitch and Aggelos Liapis 
Vasilije Kokotovich and Kees Dorst2495

The cycle of interdisciplinary learning and theory-solution building in design research

Young-ae Hahn

Don't Look Back: The Paradoxical Role of Recording in the Fashion Design Process

Helen McGilp, Claudia Eckert and Christopher F Earl

Contrasting similarities and differences between academia and industry: evaluating processes used for product development.

Nathan Kotlarewski, Christine Thong, Blair Kuys and Evan Danahay

What is the Nature and Intended Use of Design Methods?.

Colin M. Gray

Becoming a More User-Centred Organization: A Design Tool to Support Transformation.

Lennart Kaland and Christine de Lille

$$
\text { - Volume } 7 \text { - }
$$

SECTION 16

DESIGN RESEARCH - HISTORY, THEORY, PRACTICE: HISTORIES FOR FUTURE-FOCUSED THINKING

Introduction: Design Research - History, Theory, Practice: Histories for Future-Focused Thinking

Harriet Atkinson and Maya Rae Oppenheimer

The Structure of Design Processes: ideal and reality in Bruce Archer's 1968 doctoral thesis

Stephen Boyd Davis and Simone Gristwood

Closing the circle.

Douglas Tomkin

Re-integrating Design Education: Lessons from History

Peter A. Hall

(Re)working the Past, (Dis)playing the Future. Italy: The New Domestic Landscape at MoMA, 1972

Ingrid Halland Rashidi

Recommendations to rebuild the body of feminist work in industrial design

Isabel Prochner and Anne Marchand

Design practice and design research: finally together?

Kees Dorst

Design Research is Alive and Kicking.

Paul A. Rodgers and Joyce S.R. Yee

Reverse Innovation: How Has Design in the Greater Pearl River Delta Region Changed the World ....

Ningchang Zhou and Tao Huang

Beautiful Nerds: Growing a rigorous design research dialogue in the Irish context.

Adam de Eyto Carmel Maher, Mark Hadfield and Maggie Hutchings

Design Research in the East - at Universities and the Board of Industrial Design of the GDR between the 1960s and 1990

Sylvia Wölfel and Christian Wölfel

International Norms and Local Design Research: ICSID and the Promotion of Industrial Design in Latin America, 1970-1979

Tania Messell

SECTION 17

DESIGN-ING AND CREATIVE PHILOSOPHIES

Introduction: Design-ing and Creative Philosophies

Betti Marenko

Probing the future by anticipative design acts.

Annelies De Smet and Nel Janssens

Making polychronic objects for a networked society

Jane Norris

Responsibility in design: applying the philosophy of Gilbert Simondon

Sander Mulder

Space as a Becoming: Fresh Water Expo Pavilion as a Creative Practice for an Architecture to Come

Emine Görgül

The Foam: a Possible Model for the Motion Graphic Design

Anamaria Galeotti and Clice Mazzilli

Experience - A Central Concept in Design and its Roots in the History of Science

Johannes Uhlmann, Christian Wölfel and Jens Krzywinski 
Introduction: Embodied Making and Learning

Marte S. Gulliksen, Camilla Groth, Maarit Mäkelä and Pirita Seitamaa-Hakkarainen

The role of sensory experiences and emotions in craft practice

Camilla Groth

Learning to learn: What can be learned from first-hand experience with materials? ...

Biljana C. Fredriksen

Why making matters-developing an interdisciplinary research project on how embodied making may contribute to learning ...

Marte S. Gulliksen

Physiological measurements of drawing and forming activities 2941

Marianne Leinikka, Minna Huotilainen, Pirita Seitamaa-Hakkarainen, Camilla Groth, Mimmu Rankanen and Maarit Mäkelä

Code, Decode, Recode: Constructing, deconstructing and reconstructing knowledge through making .2959

Anna Piper

Experience Labs: co-creating health and care innovations using design tools and artefacts 2965

Tara French, Gemma Teal and Sneha Raman

\section{- Volume 8-}

SECTION 19

DESIGN FOR TANGIBLE, EMBEDDED AND NETWORKED TECHNOLOGIES

Introduction: Design for Tangible, Embedded and Networked Technologies

Sarah Kettley and Anne Cranny-Francis

Designing from, with and by Data: Introducing the ablative framework.

Chris Speed and Jon Oberlander

Feel it! See it! Hear it! Probing Tangible Interaction and Data Representational Modality

Trevor Hogan and Eva Hornecker

Designing Information Feedback within Hybrid Physical/Digital Interactions

David Gullick and Paul Coulton

Harnessing the Digital Records of Everyday Things

Dimitrios Darzentas, Adrian Hazzard, Michael Brown, Martin Flintham and Steve Benford

A Toaster For Life: Using Design Fiction To Facilitate Discussion On The Creation Of A Sustainable Internet of Things

Michael Stead

Making Service Design in a Digital Business.

Piia Rytilahti, Simo Rontti, Titta Jylkäs, Mira Alhonsuo, Hanna-Riina Vuontisjärvi and Laura Laivamaa

Ad Hoc Pairings: Semantic Relationships and Mobile Devices

Jason O. Germany

Serious Play Strategies in the Design of Kinetic and Wearable Devices.

Lois Frankel and Ellen Hrinivich

Tangibility in e-textile participatory service design with mental health participants

Sarah Kettley, Anna Sadkowska and Rachel Lucas

Wearable Sensory Devices for Children in Play Areas

Cai-Ru Liao, Wen-Huei Chou and Chung-Wen Hung

Intuitive Interaction in a Mixed Reality System

Shital Desai, Alethea Blackler and Vesna Popovic

From nano to macro: material inspiration within ubiquitous computing research

Isabel Paiva

\section{SECTION 20}

Experiential Knowledge

Introduction: Experiential Knowledge

Nithikul Nimkulrat

Double-loop reflective practice as an approach to understanding knowledge and experience....

John Gribbin, Mersha Aftab, Robert Young and Sumin Park

Designing "little worlds" in Walnut Park: How architects adopted an ethnographic case study on living with dementia.....

Valerie Van der Linden, Iris Van Steenwinkel, Hua Dong and Ann Heylighen

Bonding through Designing; how a participatory approach to videography can catalyse an emotive and reflective dialogue with young people.

Marianne McAra

Capturing architects' designerly ways of knowing about users: Exploring an ethnographic research approach.

Valerie Van der Linden, Hua Dong and Ann Heylighen

SECTION 21

INCLUSIVE DESIGN

Introduction: Inclusive Design

Hua Dong 
Designing for older people: But who is an older person?

Raghavendra Reddy Gudur, Alethea Blackler, Vesna Popovic and Doug Mahar

Towards designing inclusion: insights from a user data collection study in China

Weining Ning and Hua Dong

'Difficult' packaging for older Chinese adults

Xuezi Ma, Hua Dong

Crafted with Care: Reflections from co-designing wearable technologies with care home residents

Christopher Sze Chong Lim and Sara Nevay

To Shed Some Light on Empowerment: Towards Designing for Embodied Functionality .....

Jelle van Dijk and Fenne Verhoeven

Measuring Product-Related Stigma in Design.

Kristof Vaes, Pieter Jan Stappers and Achiel Standaert

Towards more culturally inclusive communication design practices: exploring creative participation between non-Indigenous and

Indigenous people in Australia

Nicola St John

Designing meaningful vehicle for older users: culture, technology, and experience.

Chao Zhao, Vesna Popovic and Xiaobo Lu

Towards Innovative and Inclusive Architecture 3393

Sidse Grangaard

Hidden public spaces: when a university campus becomes a place for communities. 3407

Davide Fassi, Laura Galluzzo and Liat Rogel

- Volume 9 -

SECTION 22

FOOD AND EATING DESIGN

Introduction: Food and Eating Design.

Hendrik N.J. Schifferstein

Designing with Empathy: Implications for Food Design

Hafdís Sunna Hermannsdóttir, Cecilie Dawes, Hanne Gideonsen and Eva De Moor

Designing for sustainability: a dialogue-based approach to the design of food packaging experiences.

Zoi Stergiadou, Jenny Darzentas and Spyros Bofylatos

Towards a sensory congruent beer bottle: Consumer associations between beer brands, flavours, and bottle designs ....

Anna Fenko, Sanne Heiltjes and Lianne van den Berg-Weitzel

SECTION 23

OBJECTS, PRACTICES, EXPERIENCES AND NETWORKS

Introduction: Objects, Practices, Experiences and Networks.

Tom Fisher and Lorraine Gamman

Stories in a Beespoon: Exploring Future Folklore through Design.

Deborah Maxwell, Liz Edwards, Toby Pillatt and Niamh Downing

Uber and Language/Action Theory

Michael Arnold Mages

Emotional Fit: Developing a new fashion design methodology for mature women...

Katherine Townsend, Ania Sadkowska and Juliana Sissons

From Afterthought to Precondition: re-engaging Design Ethics from Technology, Sustainability, and Responsibility

Jeffrey Chan

Design for Resourceful Ageing: Intervening in the Ethics of Gerontechnology

Elisa Giaccardi, Lenneke Kuijer and Louis Neven

SECTION 24

REFRAMING THE PARADOX - EXAMINING THE INTERSECTIONS BETWEEN EVIDENCE-BASED DESIGN AND DESIGN FOR THE PUBLIC SECTOR

Introduction: Reframing the Paradox - Evidence-based Design and Design for the Public Sector. 3569

Luke Feast

Open Practices: lessons from co-design of public services for behaviour change.

Simon O'Rafferty, Adam DeEyto and Huw Lewis

Capturing the "How": Showing the value of co-design through creative evaluation

Arthi Kanchana Manohar, Madeline Smith and Mirian Calvo

Design in the Time of Policy Problems.

Lucy Kimbell

The introduction of design to policymaking: Policy Lab and the UK government.

Jocelyn Bailey and Peter Lloyd

Problematizing Evidence-Based Design: A Case Study of Designing for Services in the Finnish Government 3635 Helena Sustar and Luke Feast 
Designed Engagement

Gemma Teal and Tara French

Public design and social innovation: Learning from applied research ...

Caroline Gagnon and Valérie Côté

Design as analysis: examining the use of precedents in parliamentary debate.

Darren Umney, Christopher Earl and Peter Lloyd

Exposing charities to design-led approaches through design research.

Laura Warwick and Robert Djaelani

- Volume 10 -

SECTION 25

SUSTAINABLE DESIGN

Introduction: Sustainable Design

Rhoda Trimingham

Design for Sustainability: An Evolutionary Review

Fabrizio Ceschin and Idil Gaziulusoy

Consumer Product Design and Innovation: Past, present and future.

Robin Roy

Product-Service Systems or Service Design ‘By-Products’? A Systems Thinking Approach

John Darzentas and Jenny Darzentas

Supporting SMEs in designing sustainable business models for energy access for the BoP: a strategic design tool......

Silvia Emili, Fabrizio Ceschin and David Harrison

Extending clothing lifetimes: an exploration of design and supply chain challenges

Lynn Oxborrow and Stella Claxton

The effect of consumer attitudes on design for product longevity: The case of the fashion industry.....

Angharad McLaren, Helen Goworek, Tim Cooper, Lynn Oxborrow and Helen Hill

Framing Complexity in Design through theories of Social Practice and Structuration: A comparative case study of urban cycling .........3847

Tobias Barnes Hofmeister and Martina Keitsch

Integrating Sustainability Literacy into Design Education.

Andrea Quam

Design of resilient consumer products

Anders Haug

Designing for Sustainable Transition through Value Sensitive Design.

Luisa Sze-man Mok, Sampsa Hyysalo and Jenni Väänänen

Mixing up everyday life - uncovering sufficiency practices through designerly tools

Miriam Lahusen, Susanne Ritzmann, Florian Sametinger, Gesche Joost and Lars-Arvid Brischke

Give car-free life a try: Designing seeds for changed practices

Mia Hesselgren and Hanna Hasselqvist

A sociotechnical framework for the design of collaborative services: diagnosis and conceptualisation.

Joon Sang Baek, Sojung Kim and Yoonee Pahk

Moving Textile Artisans' Communities towards a Sustainable Future - A Theoretical Framework

Francesco Mazzarella, Carolina Escobar-Tello and Val Mitchell

Sharing 10 years of experience with class AUP0479 - Design for Sustainability .

Maria Cecília Santos, Tatiana Sakurai and Verena Lima

SECTION 26

THE POLITICS OF COMMONING AND DESIGN

Introduction: The Politics of Commoning and Design .4005

Bianca Elzenbaumer, Valeria Graziano and Kim Trogal

Commons \& community economies: entry points to design for eco-social justice?

Fabio Franz and Bianca Elzenbaumer

Design Togetherness, Pluralism and Convergence 4029

Monica Lindh Karlsson and Johan Redström

Designing participation for commoning in temporary spaces: A case study in Aveiro, Portugal 4045

Janaina Teles Barbosa, Maria Hellström Reimer and João Almeida Mota

From Rules in Use to Culture in Use - Commoning and Infrastructuring Practices in an Open Cultural Movement. 4063 Sanna Marttila

Index of Authors 4080 
Volume 8 


\title{
Introduction: Inclusive Design
}

\author{
Hua Dong
}

Tongji University

DOI: $10.21606 / \mathrm{drs} .2016 .610$

The Inclusive Design Research Special Interest Group (Inclusive SIG) of the Design Research Society provides an international platform for researchers, design practitioners, and the general public to exchange knowledge about accessible and attractive design and to empower wider participation in the design process.

The main foci of the Inclusive SIG include:

- Building and advancing knowledge for inclusive design and research

- Creating and evaluating tools and methods for inclusive design practice

- Developing strategies for engaging designers and the public

- Exploring new territories of inclusive design for the majority world

- Through these activities, we aim:

- To share best practice in contemporary design, research, education, and public engagement

- To keep pushing the boundaries of inclusive design and explore its potential in different contexts

As one of the special interest groups of the Design Research Society (DRS), Inclusive SIG organizes symposia on a regular basis, and the inclusive design session for the 2016 DRS received 18 papers, in addition to the relevant submissions from the open call. Following a thorough review process and strict selection criteria, 11 papers were selected for presentation at the conference. These papers cover a diverse range of topics, from redefining ageing, measuring user capabilities, to assessing product-related stigma. For example, the paper 'Designing for older people: But who is an older person?' by Raghavendra et al. from University of Canberra, Australia, addresses one of the critical aspects of inclusive design discourses, i.e. the definition of ageing. It reports the experiment investigating if redundancy in interface design can facilitate intuitive use in older users and 
users with low technological prior experience. The findings proved that diversity in older age groups presents a great challenge in developing intuitively usable interfaces. The research suggests that looking at a target group based on their cognitive abilities instead of chronological age will provide an much more effective approach in dealing with this challenge.

Understanding user capability has been a topic for inclusive design for many years; the main challenges include: lack of appropriate definition of product-design related capabilities or related measurement scales and methods. The paper 'Towards designing inclusion: insights from a user data collection study in China' by Ning and Dong from Tongji University, has attempted to collect user data of 130 older persons in China, covering many areas of competence, from the more quantitative domain of biomechanics, interaction, to more subjective and qualitative areas (e.g. comfort). As a pilot study in collecting Chinese older people's capabilities in relation to product use, the study explores the relation between 'maximum' and 'comfortable' capability measurements, and verifies the feasibility of establishing predictive models of successful product interactions in the 50-70 user group. This study has provided promising directions for further exploration of user data.

With increasing longevity and changes in population demographics; designers, engineers and architects are faced with the challenge of providing older adults with enabling technologies and home environments that facilitate physical activity and wellbeing. For instance, there is an overall theme that older people encounter difficulty in opening household packaging for a variety of reasons. Ma and Dong's paper reports upon a survey-based investigation into such difficulties encountered by older Chinese individuals. The paper not only identifies difficult packaging types from the older users' perspectives, but also tackles the problem by considering several critical design research areas such as user participation in the design process, end user acceptance, decision-making and inclusion.

Lim and Nevay from the University of Dundee also focuses on the design process. Their paper reports a co-design project, involving care-home residents, to address the issue of acceptance and adoption of wearable technologies for older adults to monitor their activities and movements. It describes a 'craft-based' approach 'to allow designers to understand and uncover people's capabilities and needs in a non-intrusive and empathic way'. The paper raises, at the outset, the issue of non-compliance of current wearable technologies, and posits that co-design of these with older adults - through a 'crafting' process - will provide a greater sense of ownership and acceptability of designs. The authors' particular emphasis is on the 'crafting' of these artefacts, suggesting this is being led by 'nontechies' which may prove of significance in the design of acceptable technologies.

Dijk and Verhoeven's paper 'to shed some light on empowerment: towards designing for embodied functionality' uses a participatory design project to examine whether an interactive lighting system could empower a person with autism by supporting domestic activities. Reflecting on the case the authors develop the vision of Embodied Functionality (EF) and argue that designing for EF goes beyond 'distributing' information technology in the 
environment and opens up an alternative design space, holding the promise of a more successful appropriation of interactive (assistive) products into people's everyday lives.

Stigma is a subject frequently discussed within the field of inclusive design, however measurement of this trait is under-explored. The paper 'Product stigmaticity: measuring product-related stigma' (by Kristof Romain Viktor Vaes' Pieter Jan Stappers' Achiel Standaert) presents two measuring techniques that aim to objectively assess the 'degree' of 'productrelated stigma' (PRS) that is 'attached' to products. It is argued that both experimental techniques are predominantly suited as comparison tools, able to compare products on their PRS-eliciting potential. It is expected that designers and developers to use these results to justify design decisions with quantitative data, to assess which product properties have influenced certain reactions, and to what extent subsequent improvements have been successful.

The selected papers not only address the traditional dimensions of inclusive design, i.e. young-old, able-disable, professional-lay, but also raise emerging topics such as participatory action and the cultural aspect of inclusive design.

Through case study analysis, Nicola St John's paper 'Towards more culturally inclusive communication design practices: exploring creative participation between non-Indigenous and Indigenous people in Australia' explores and discusses a more culturally inclusive communication design practice particularly in relation to framing a process for creative participation and creation between Non-Indigenous and Indigenous people within Australia. It draws from and applies principles of Transformative Participatory Action research to communication design practice. This approach moves away from co-design and participatory design models to focus more on participatory action, active engagement and empowering Indigenous communities through design.

Zhao Chao, Popovic Vesna and Lu Xiaobo's paper 'Designing meaningful vehicles for older users: culture, technology, and experience' investigates Chinese middle-aged vehicle users and older vehicle users pertinent to their current travel experience and future travel needs. The study utilizes grounded theory to analyze the travel activities of two age cohorts and compare the travel-needs-influencing factors. The researchers have adapted technique of interviews, logbook and co-discovery to help collect data and explore these factors within the Chinese cultural frameworks. The study contributes to a framework and method for automotive designers to incorporate user feedback in a human-centered design process, aiming at designing vehicles that are both meaningful, functional and locally relevant for an aging population in China.

Grangaard's paper 'Towards an innovative and inclusive architecture' describes a study investigating how architectural firms and organizations related to disability in the built environment perceive and work with the Danish Building Regulations Accessibility

Requirements. It discusses about accessibility regulations, in particular the challenges they present by forcing the firms to consistently meet the prescribed requirements as opposed to 
the behavioural/experiential needs of the users, when not all users have the same accessibility needs.

David Fassi, Laura Galluzzo and Liat Rogel report a series of design interventions that open up the Bovisa Campus of the Politecnico di Milano as a hidden space to its surrounding communities, aiming at making normally hidden marginalized public spaces within a university campus accessible to the wider community. The paper presents a means of engaging students in future thinking and how design and design education might play a more active role in enabling such practices to be more systematically developed through a series of social activities, highlighting how design research as a creative and active force invites reconsideration of ideas about design and its role in shaping our lives in more expansive ways.

With these interesting papers addressing inclusivity from a variety of perspectives, I expect that the Inclusive Design session to provide an inspirational form for discussion and debate. For example, although engaging users creatively in the design process could help increase the sense of ownership of the participants, thus increasing the acceptance of the final design, with designers being knowledge users of inclusive design knowledge, there is a challenge yet to be addressed, i.e. how such user data would be made available, accessible and attractive to designer practitioners to exploit. We hope participants will share experience and good practice and help move the filed forward. 


\title{
Hidden public spaces: when a university campus becomes a place for communities
}

\author{
Davide Fassi*, Laura Galluzzo and Liat Rogel \\ Politecnico di Milano \\ * davide.fassi@polimi.it \\ DOI: 10.21606/drs.2016.377
}

\begin{abstract}
C'è spazio per tutti/There's room for one more" is an event that took place in November 2011 at the Milano Bovisa Durando campus of Politecnico di Milano, Italy with the purpose of opening up the public spaces of the university to the inhabitants of that area through a series of design actions to offer opportunities for understanding, observation and enjoyment of a public space. That was the beginning of a series of design for social innovation projects connected to the Bovisa neighbourhood organized over the following years. In this paper we will describe the need to open-up hidden (unknown) public spaces like the Milano Bovisa Durando campus and the idea that through small rapid design experiments we can immediately test the efficacy of tools made to enable people's and communities' use of the public space.
\end{abstract}

Keywords: Hidden public space, Toolkit, Communities, University campus

\section{Introduction}

\subsection{The city and the need for communities.}

The activity of communities in public spaces is a key feature of moving towards a more sustainable way of living in the urban area. It is not surprising that the city has been a favourite discussion topic (for bad or good) in the recent years, and for a good reason: the world's population is becoming concentrated in urban areas; therefore, taking care of the city means taking care of large numbers of people. The common image of the expanding city, however, is far from ideal. The most frequent words describing urban realities are: social exclusion, alienation, segregation and loneliness. More than a crisis of the city we should rather talk about a crisis of city life. Globally, cities are growing, changing and developing, and international metropolises share more features than they do with their local contexts (Sassen, 2004). It has been clear for some time now that new development 
strategies are needed, but: where to begin? In the United States many authors have criticized urban planning processes and accused them of not considering the residents' needs, some offering concrete solutions and alternatives. In 1970, Richard Sennet (Sennet, 1970) wrote about the crisis of the city, introducing an idea that differed from that of Jane Jacobs in "The Death and Life of Great American Cities" (Jacobs, 1961). Jacobs, he says, is nostalgic about the past and the relationships between people in small towns; she tends to suggest a restoration of past conditions. Sennet (1970) states we can not think that the past can give us elements to improve our present city problems, as the solutions we want must be adapted to an affluent, technological era. The answer is probably to be found between these two arguments, or perhaps they are not so far away from each other to begin with. They both conclude that communities must have a need for, and the will to re-reach some values that have been lost in modern urban life, such as mutual support and conviviality. Although written some years ago, these books still represent important and contemporary criticisms of today's urban planning. More and more people in cities are finding creative ways of refilling those gaps. They collaborate in various ways using new and old tools. These creative communities (Meroni, 2007) are producing social innovation. They are a sustainable resource that must not only be recognized but also supported and disseminated. According to Manzini (2015), "social innovations are solutions based on new social forms and economical models. They are those social changes towards sustainability when they can reduce the environmental impact, regenerate common goods and social fabric". These innovations often deal with public space because communities often act in and for public space. What kind of public spaces and how they are connected with the university realm is the key issue to be discussed in the next paragraph.

\subsection{Space for urban communities}

Independent events have started to grow in the city, in those areas where there are particular problems which are shown by increasing the consciousness of the residents (Bostjan, 2010:22). The city is read as an independent container of public spaces even if, according to Rem Koolhas, the distinction between public and private is nowadays outdated. We are faced with residual spaces, abandoned and not controlled. Giovanna Piccinno in Space Design (Piccinno, 2008, p.11) says that "[...] the contemporary designer must listen to new places (without distinction between places and non-places) and new citizens (local or itinerant) and answer in terms of design with the operative tools he has.[...]". The action is generally done in places which are not offered freely or donated, but, on the contrary, are lent or temporarily given for a specific use (Haydn and Temel, 2006). And we are not only talking about those places recognized as possible sites for temporary urban solutions (Fassi, $2012)^{1}$ (squares, parks, stadiums), but about those areas at the margins, which have been

\footnotetext{
1 "Temporary urban solutions" (TUS) are project answers put in place by professionals in a sector or by groups of people lead by a team of

project specialists, which change into devices, set up, collective actions, emergency displays, project strategies which contaminate the single building, an agglomerate of them, a urban interior or an open space or a passage space with a
} 
stolen from an inattentive urban planning project or infrastructures that do not enter into dialogue with their context (Navarra, 2008). ${ }^{1}$ Or it is the "space of abandonment" as the "Stalker" group defined it (Careri, 2006), which is a space "where complexity survives to the mono-functional colonization and the city experiments generating a neutral area which gives back a sense of concept to public space as a creative space and sharing space" (Romolo, 2005, p.18). Luciano Crespi (Crespi, 2009, p.20) says that the "true act of recognition of the place is only through the presence on the place itself, within the internal and external areas, whose changes need to be foreseen. Where staying means something deeper than stopping for a moment or being there by chance. Staying means the need to understand, to listen to the place, to recognize the soul" in the sense provided by Hillman (2004). The sense of ownership of space reflects the reading of the city as a "place of self-identification of the individual" which, according to Barcellona (Barcellona, 2006, p.17) "is possible through the personalization of the urban space which is at the same time the structured image of values and community bonds and the place of distinction for the relationship between single and community". Feeling an urban space means perceiving a shape of what is empty and what is full, of high and low spaces, above and below spaces, but also recognizing a system of relationships between the people who live in these spaces, the neighborhood, the life in the residential areas, true centres of communication (Barcellona, 2006, p.17).

As Francesca Zajczyk states, the neighborhood is a portion of an urban area, both physical and social, where plenty of resources, factors and critical situations can be found. It underlines the identification with the local side of the city, is able to read the micro-social dynamics and to express the relationship among citizens/social groups and urban areas (Zajczyk, 2008).

\section{Hidden public spaces}

Sometimes public space is not obvious. When the borders between private and public are blurred, new kind of spaces are born that even if they belong to everyone they are not visually public. These are public spaces we define as 'hidden'. Traditional houses and apartment blocks in Milan were designed to have an inner courtyard that generally gave access to other buildings inside, but is not seen from the outside. These courtyards have direct access from the streets that brings the user to a semi-private area. It means they are open to the public even if they belong to a private property. It is this feature that makes them hidden places, since citizens, tourists or casual passers-by are not directly aware of them and could only discover them if needing access. This courtyard distribution system comes from the farmhouses ("cascina"), a traditional system of buildings, now found only in

\footnotetext{
process of functional and perceptive change on the occasion of temporary events linked to hospitality, to sales, to leisure time, to entertainment" in Fassi, D., Temporary Urban Solutions, Maggioli, Rimini, 2012, p.12.

1 "Infrastructures compose an articulate vocabulary of shapes which defining the covered spaces with a variable height, interfere with the urban network. Thus there are some special points which form residual spaces, not accessible to cars and separated by houses. In these knots there are the spontaneous and temporary actions which bring to their use with absolutely variable ways and time", Navarra, Marco, (a cura di), Repairing cities, Siracusa, LetteraVentidue edizioni, 2008, p.14
} 
the countryside close to Milan, which serves both residential and work purposes. In Milan we may find "a city within a city" ${ }^{1}$ made up of these hidden places: some are unknown even if located on main urban pathways, other are invisible because they are located in an urban "backstage". They may be classified as those that have a cultural heritage value (material or immaterial) and as those that have potential to be explored and valued in a community. Public university campuses are included in this latter category. Even if they are used by a specific kind of user (people who study or work there) and are perceived by other people as a private area (belonging to university); in most cases, however, campus spaces are public. According to Zukin (Zukin, 1995) "public spaces are important because they are places where strangers mingle freely" and since "metropolitan universities offer the possibility of creating a dialogue across the difference that largely defines metropolitan life in our time" (Bender, 1998) we may consider the campus located in the Bovisa area in Milan as an example of how this dialogue could be developed by merging the neighborhood and the academic staff. The crucial location of this campus is described in the next paragraph where a strong connection among spaces, buildings and communities emerge.

\subsection{The Milano Bovisa Durando campus}

Bovisa is an ex-industrial district. In the second half of the $20^{\text {th }}$ century it was subject to great change due to the removal of almost all the industries. The district was left with many abandoned areas that were soon to become a problem for the residents as they attracted homeless people, drug dealers etc. The quarter had lost its main reason of existence and did not initially transform into a suitable residential area with appropriate public spaces. The population has become more and more mixed as immigrants came to the district. Various re-construction projects slowly began in the area and the biggest one was the creation of two university campuses for the Politecnico di Milano, Milano Bovisa Durando and Milano Bovisa La. The arrival of Politecnico di Milano in the Bovisa area changed the district again, bringing in young students and commercial activities related to them. The new life of the neighbourhood has indeed brought an improvement of public transportation and the building of new residential areas, but public spaces like green areas or squares with street furniture are still missing. The Milano Bovisa Durando campus, hosting the School of Design, was built at the end of the 90s on the grounds of "Ceretti \& Tanfani", a long-established company that had produced cable railways and had made Bovisa a working class district. The place is part of the historical memory of the local inhabitants. Today it is a green space with places to sit as well as a cafe. In spring and summer many students sit outside, enjoy the sun and doing outdoor activities. It is a hidden public space since no one beside the university community uses it as such. The campus remains an "island for students" and most of the people who once knew the place as a former industry did not even have the opportunity to see how it has transformed. The two types of 'users' (university community and the local

\footnotetext{
${ }^{1}$ The hidden Milano is now at the centre of a tourist promotion activity by the city council. It is described in detail at www.turismo.milano.it
} 
residents) have very few contact points in common. The potential for improvement the campus could have offered is huge, but unfortunately it has not been fulfilled.

\section{Hidden public space and design education experiment}

Following the premises described in the previous paragraph, as a research team dealing with design for social innovation, we started to investigate how this hidden public space could have been opened up by the university community (students/designers/staff) to create extra space in the everyday life of permanent residents. To answer this question we tested a design education experiment based on user/community centered design, using co-design methods and creating a deep immersive experience in the neighborhood for postgraduate students. We embraced the theory of designers as solution-developers for people to one that allows people to design by and for themselves (Brown, 2009) asking the students to open a dialogue with the local community, with associations or informal groups. In 2011, when we established a workshop at the School of Design this offer was addressed to postgraduate students from MSc Interior, Communication. Fashion, Product Service System and Product Design. This created an intra-disciplinary class that was useful to merge skills, competences and approaches since the students were working in teams. It was the first time that a course with a strong connection with the neighbourhood and with a deep in-the-field immersion was held at the School of Design. At the same time, a Polisocial programme was starting: a programme for university social responsibility. Polisocial aims to place the university in close contact with the dynamics of change in society, extending the university's mission to social issues and needs that arise from the region, on both a local and global level. Polisocial promotes and encourages new multidisciplinary approaches in human and social development, developing training opportunities and opportunities for exchange and research offered to students, researchers, and the university's teaching and technicaladministrative staff. "The goal is to foster a responsible attitude and to develop skills, expertise and new values, in future generations of professionals and citizens, increasingly more aware and prepared to handle ethical challenges" ${ }^{1}$.

\subsection{Methodology}

A Participatory Action Research (PAR) was used to define the workshop activities. At the heart of this process is five-day workshop for design students ending in a one-day event to test the ideas immediately. Since a prototype can not only be viewed as a thing (an object) (Anders et al., 2011) but also as socio-material relations where matters of concerns can be dealt with (Björgvinsson et al 2010), we encouraged the students to work on both these features. That is why the prototyping action was connected to an event where not only product/spaces/service are shown and but where relations take place helped by the use of toolkits. The toolkits are made to be used directly by the end users, thus empowering them to develop certain actions or to achieve specific goals. This kind of fast, small design

\footnotetext{
${ }^{1} \mathrm{http}: / /$ www.polisocial.polimi.it/it/home/
} 
experiments allowed us to reach quick conclusions and continue towards more stable and organized solutions (Fassi, Meroni, Simeone, 2013). Our PAR process was organized in this way:

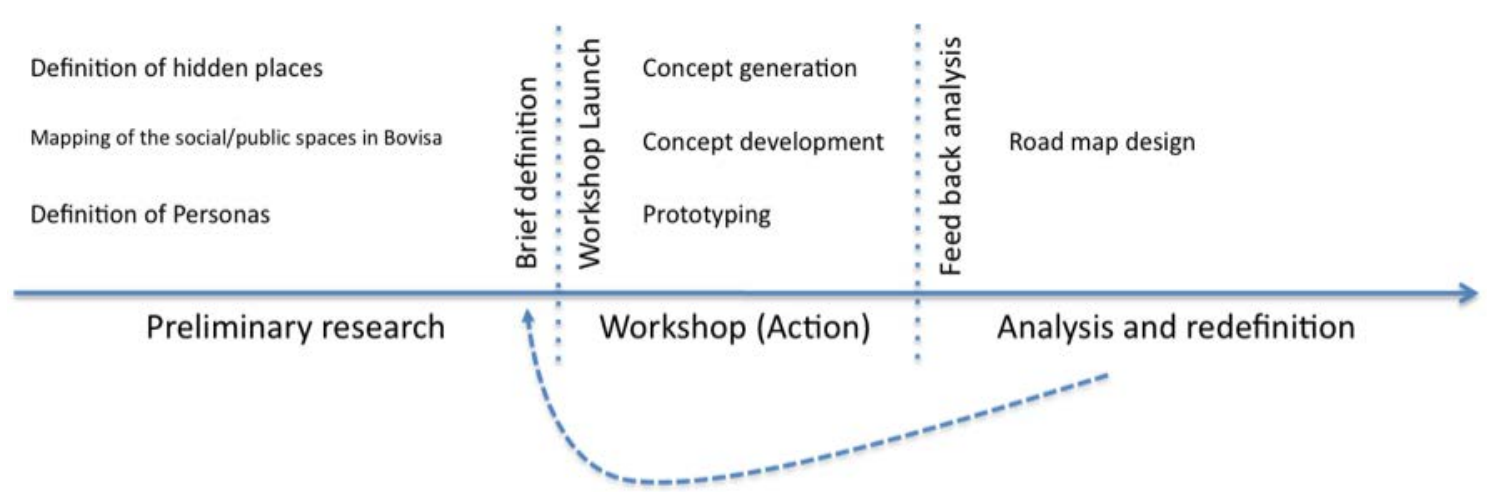

Figure 1: PAR (Participatory Action Research) Model

The research began with a preliminary study of available literature about conventional and non-conventional public spaces. Through this, a definition of hidden public spaces was made available (see above). The Campus Bovisa area was then chosen in order to generate an applied activity on the topic. The second part of the preliminary research is context-related and included the definition of personas and the mapping of the area's social places.

\subsection{Mapping of the social/public places of Bovisa}

An immersion took place in the social/public places of Bovisa, including schools, local associations, public services, libraries, parks etc. From this mapping it became clear that public areas that involve the whole community are missing and the existing social places are related to specific communities and are semi-private. Some of the hypotheses previously formulated were confirmed by this phase of the research: the Milano Bovisa Durando campus is not considered a public space for the residents and there is a vast interest in having more space available for age- and culture-crossing activities. Also, the campus is very intriguing for the people and most of them, especially the retired people, expressed a need and real curiosity in seeing what Politecnico di Milano is and how it uses those areas. Most of the new local shops that were opened after the arrival of Politecnico di Milano are used by the university community and experience a loss of customers at weekends when there are no activities in the campus.

The research and mapping brought a definition of the brief to the student workshop. The students were asked to:

- develop ideas for collaborative services on the campus area for local residents

- design a toolkit to enable people to participate in/initiate the services 
- test part of the toolkit or prototype the service where needed, in the one-day event scheduled after the workshop.

- let the people do social activities in a "design context" (i.e. School of Design spaces of the campus)

A few more specific topics emerged from the first part of the research: 1) the lack of green spaces and the relationship with nature, 2) the absence of a cultural heritage related to everyday spaces 3 ) the desire for a sense of community and the need for dedicated spaces, and 4) a constant need to re-vitalize the neighborhood from a cultural point of view. These results produced four topics that were presented to the students by the tutors as part of the brief:

- Food: green spaces, contact with nature, cooking

- Places: local cultural heritage valorisation, explanation of Politecnico di Milano facilities

- Free time: public sport facilities or spaces, spaces for group activities

- Entertainment: events, exhibition, open air activities.

\section{The workshop}

\subsection{Concept generation for services, concept development:}

42 international students joined the workshop as an elective course on the MSc Product Service System. Students were asked to split in teams and work on one of the four topics assigned. One team focused on managing Saturday morning events, including communication strategy, fund-raising to produce toolkits, logistic issues and promotion/advertising to guarantee an adequate number of people would attend. On Wednesday the event-managing team went to the local market to promote the Saturday event through a flash-mob that focused on the idea of providing a chair for people to come and sit with them to have a chat in a public space. It was a way of letting local people know that a "hidden place" was asking to be discovered. ${ }^{1}$ During the week the same team went to the mapped schools to advertise the event to the children and to their parents/grandparents at the end of the school day to spread the word. Small groups of students worked on concept generation for the first two days and then moved on to the development of the project and the production of the "material" outputs included in the toolkits. Five concepts were presented according to the topics suggested and the "personas" identified. Workshops with children, gardening, tours of the campus, and light sports activities were some of the visions designed by the students that received detailed feedback in a session where students and tutors were to produce five projects to be developed in the following three days, which would then be presented at "C'è spazio per tutti/There's room for one more" event. During

\footnotetext{
${ }^{1}$ Short movie about the flash-mob can be viewed at http://www.youtube.com/watch?v=PzyhIXTBhD8
} 
the second part of the week there was a huge effort by the students to get in contact with local shops for the supply of raw materials that would useful to the projects.

Five toolkits were designed for the five outputs of the workshop:

- "C'è giardino per tutti/There's a garden for everyone": to create a urban garden for the area in the green spaces of the campus. A community garden inside the Politecnico campus would enable people to create a community, enhancing transgenerational exchange and promoting a sustainable lifestyle

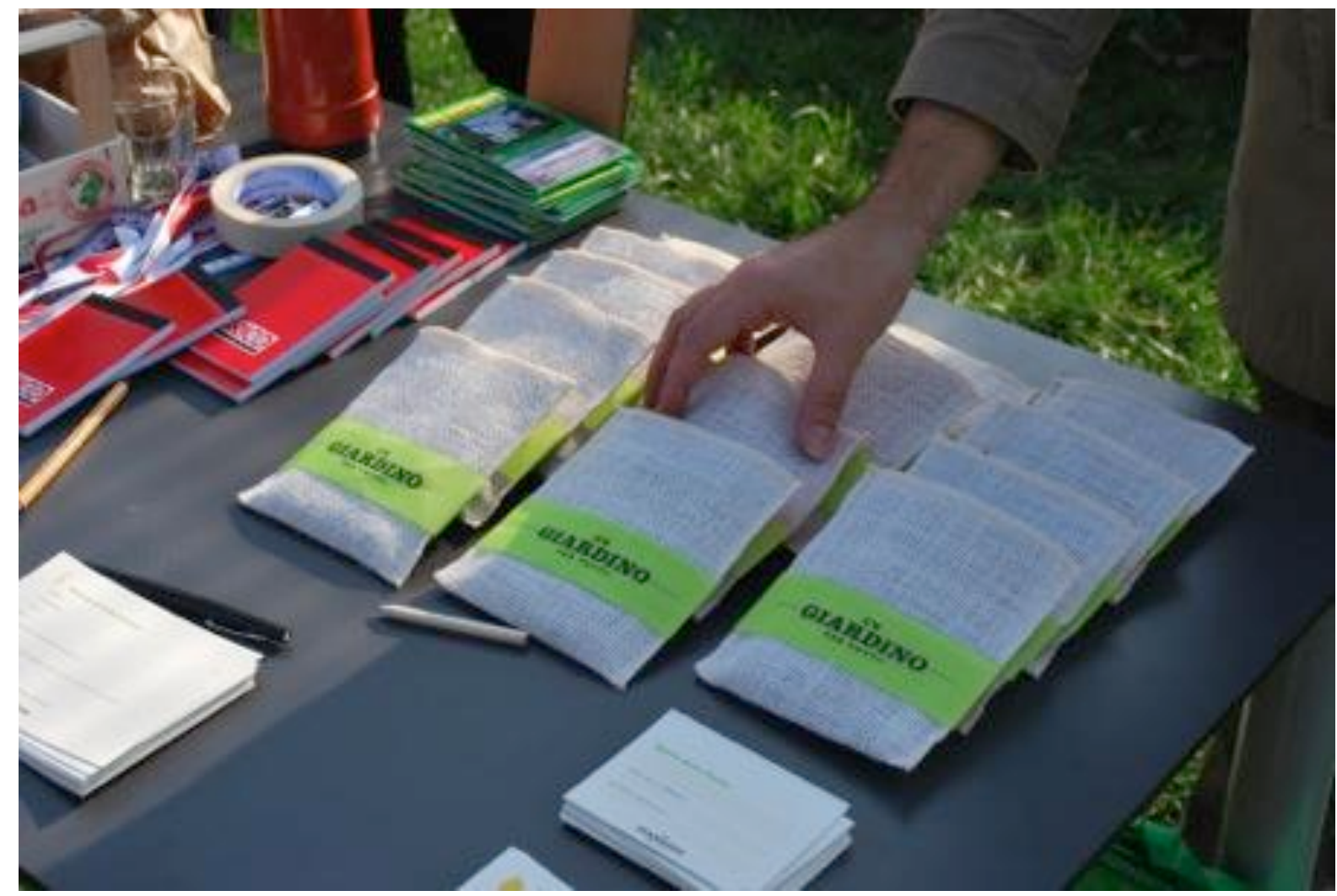

Figure 2 "C'è giardino per tutti" toolkit

- "Il mio taccuino/My notebook": to introduce the natural part of the campus to children through collecting leaves, drawing and using the "frottage" technique. The main purpose is to let children understand what the design process is through a series of guided exercises inspired by our activities. As well as new techniques, the children will learn how to discover new places and know more about specific contexts by using a different approach. 

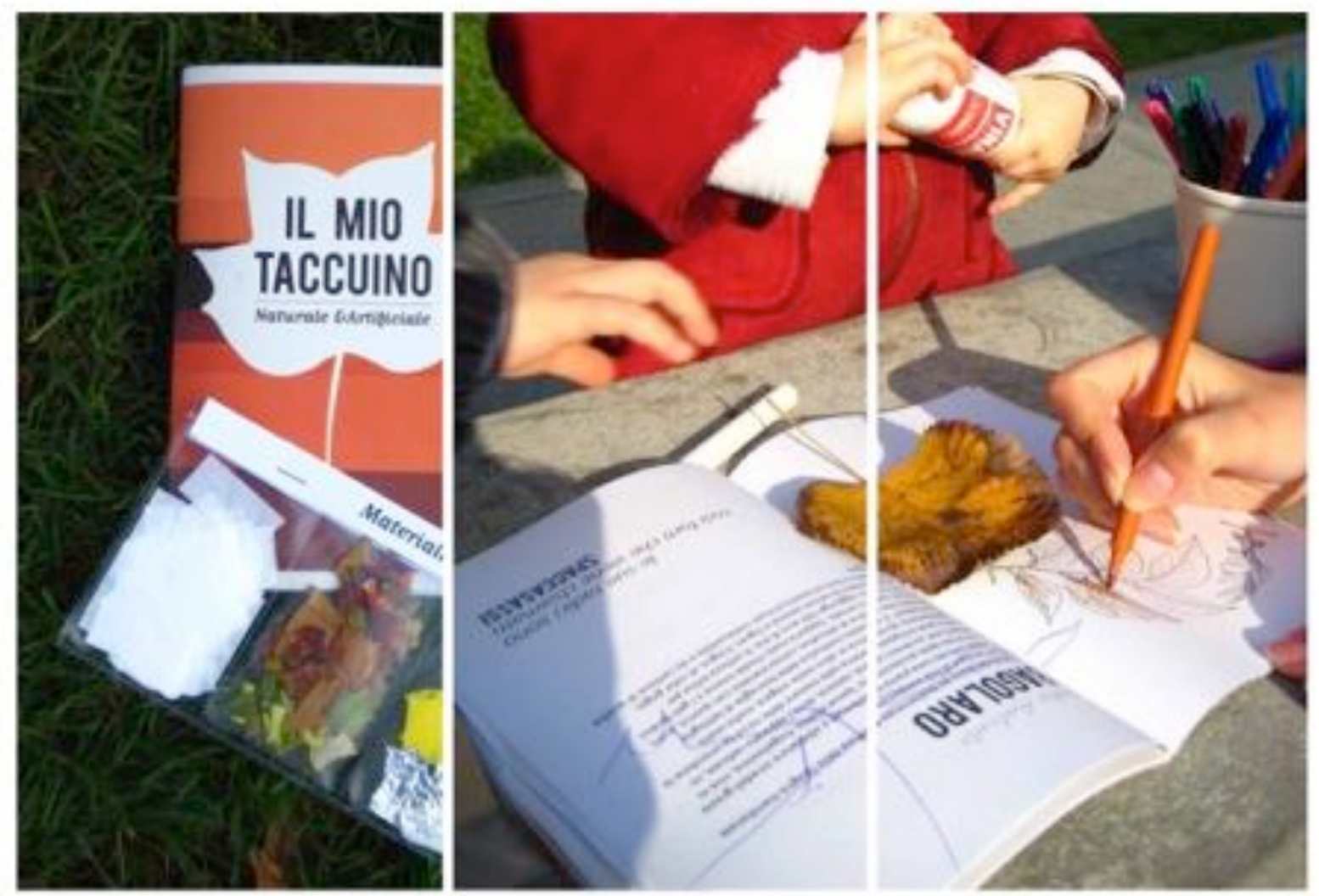

Figure 3 II Mio taccuino toolkit

- "Piccoli cuochi/Little cooks": to apply the design process to cooking according to Enzo Mari's theories, involving children. It encourages people to get to know each other and collaborate while being engaged in a cooking process which reflects the design method. The toolkit includes: 20 cards - ingredients, 20 cards - cooking utensils, 1 instruction card with rules of the game, 1 method card with recipe.

- "Poli-tour": to discover the past and present of the campus, through some traces left by the former factory "Ceretti\&Tanfani" and discovering the facilities of Politecnico di Milano. The toolkit is made up of 6 elements: a map including clues to find the path of the quest; information postcards and photo panels, providing information about the past history and the present of the campus, the red chair where people would sit and have a picture taken in the campus context.

- "Peter e Gisella": to reclaim the public space through light sports activities linked to campus areas (fig. 4). The toolkit includes 7 illustrative boards, which can be printed to create different areas where participants do different healthy activities, magenta stickers to indicate where the activities take place, and moustache stickers for the laughing activity. Users can also add new activities to customize it to their own wishes. 


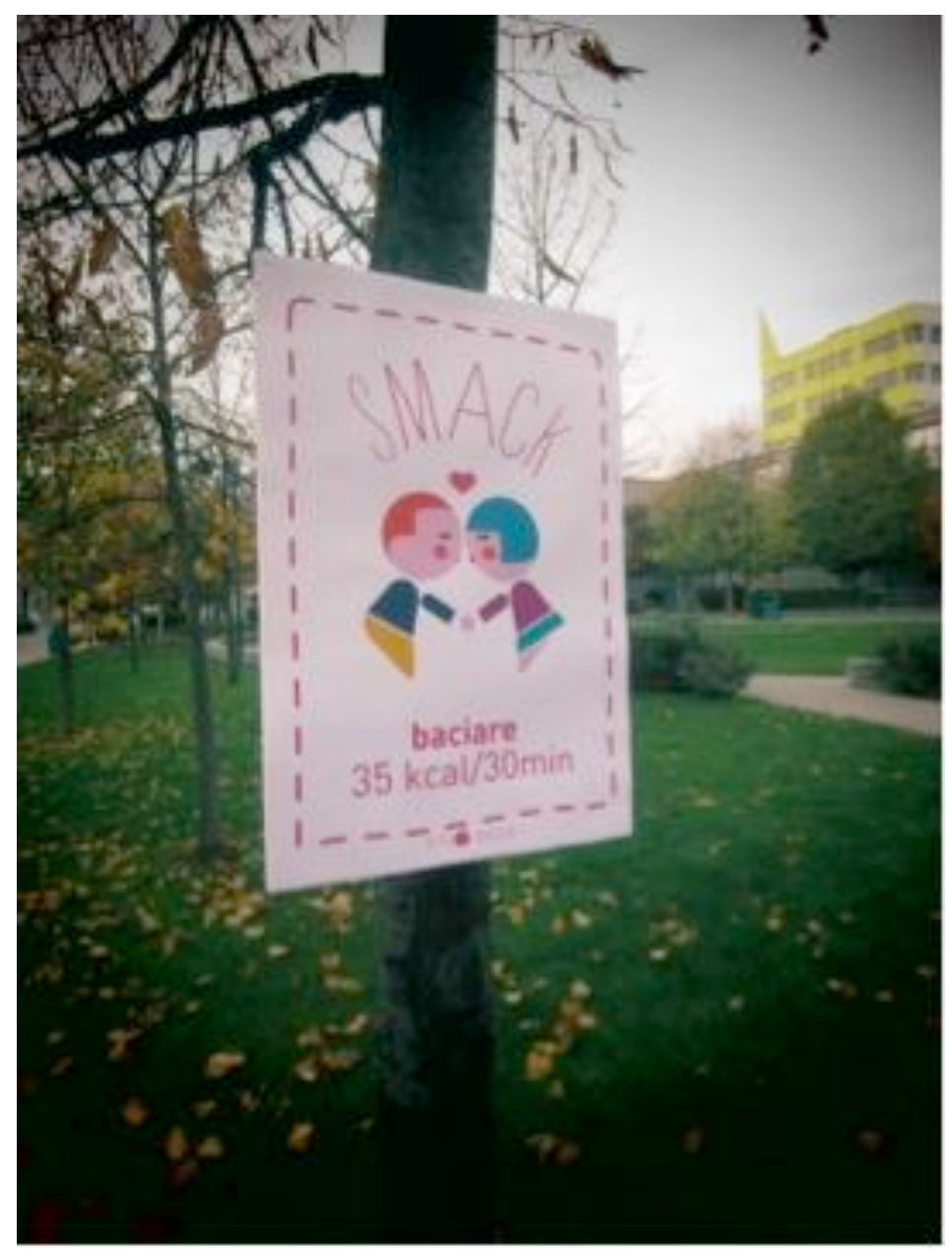

Figure 4 "Peter and Gisella" toolkit

\subsection{Prototyping of service ideas}

Some guidelines have been followed to prototype the toolkits to guarantee scientific results. First: the toolkits had to present as a physical output including the rules and tools to be used. Second: the toolkits had to be produced in a series of fifteen items (as a minimum) to allow appropriate sufficient number of people to be involved in testing them. Third: three to four facilitators had to be present to help users engage with the toolkit and use it. Fourth: the facilitators had to collect feedback directly (through an informal conversation with the users) and indirectly (through observation of the interaction between users and toolkits). Fifth: every activity had to be recorded through pictures and/or movies.

When the gates opened a reception desk was placed at the main entrance and the event managing team was in charge of welcoming the people and explaining the project. People of the neighborhood were invited to use the space (often for the first time) as a public space and they were given a map of the campus, including where they could find the toolkit to be tested. 


\subsection{Feedback.}

200 people entered the campus that day and the general feedback was positive. Feedback was collected by interviews, surveys and active observation on the day. The surveys/interviews asked mainly:

- if people could see themselves coming more frequently to the campus to use it for their own activities or enjoying the activities provided

- their opinion about the one-day event and the individual activities

- their wishes for future events in the campus

Active observation, including taking photographs and filming, was important in understanding different behaviours. The students could immediately understand if there was something in their project that needed modifying and some did it on the same day to have immediate results. Others took notes for a future design of the project. ${ }^{1}$

\section{Analysis and road map design}

The feedback was analysed into points of strength and weaknesses (as described below). In order to achieve continuity and arrive at a repeatable model we designed a road map for future steps.

\subsection{Results}

The overall results of the research have shown:

- Interest by the people to discover the campus as it is today. Many of the visitors knew the place in it former use and during this event had the chance to see it for the first time as a university campus. Elderly people were very keen to see the transformation and tell the students about what used to be there before, having a real wish to strengthen their memories.

- Understanding by the people of the new opportunities offered by the space (how they can use them). Entering the campus and participating in the initiative made people understand how they can use the space on an everyday basis. Many people showed interest in coming there with children to enjoy being in the open air or ride bicycles because the space is well-protected. Also, people involved in local associations were interested in initiating their own activities in the space. A group of neighbors was interested in maintaining the vegetable garden and creating a new green space for the neighborhood, as they do not own a private one.

- A better understanding of the local context by the university community. The event allowed the university community to know more about the context (and not only the limited places where they have lessons)

\footnotetext{
${ }^{1}$ A short movie about "C'è spazio per tutti/There's room for one more" made by the event managing student team is available at http://www.youtube.com/watch?v=atvk7kw5_Ic\&feature=related
} 
- Offering a mixed space for several categories of users. The Bovisa campus space was transformed by the designed toolkits into a multi-user space with very different activities. The people participating noticed this and the feedback was very positive.

- Generating new economic dynamics among local shops, citizens and students. The fund-raising done by the students among the local commercial activities allowed them to become acquainted with the economic (and not only social) potential of the event. Those who understood the potential of collaborating with the university showed great interest, and availability and connections were made for future projects.

- Limited time of the event. 3.5 hours is a rather limited time for an event. On one side it allowed us to achieve a good level of results and tests but, on the other, it could have been longer and lasted for the whole day so as to not only get in touch with the "morning" users of the area but also with the "afternoon/evening" ones.

- Campus boundaries. Politecnico di Milano campus has physical gates that are perceived by residents as a barrier. This created some difficulties during the event, because, even if they were open and advertised as the entrance, they were still perceived as a restriction to accessibility.

\section{Follow up and discussion}

\subsection{Follow up}

The need for spaces for the community in the city was confirmed by our PAR. According to certain targets set in the goals, the results of the "C'è spazio per tutti" workshop and event have generated scenarios that could be systematized to give the prototyped solutions a temporal continuity and interaction by generating new solutions for integration with the space. The time pattern in which the research/action was set, has been effective because there was an area of direct consciousness as to the failure or success of the project. The workshop, thanks to the Masters level students, a good mix of background and skills of the team members, and to rhythm and aims set during the initial phase, was a research method with a high level of instantaneous experimentation generating ideas to be put into effect. It soon brought results thanks to a rapid phase of development.

The hidden place started to be discovered by the neighbourhood. The depth of existing boundaries between the university area and Bovisa was decreasing through word of mouth and signals left on the campus as a memory of the event.

"C'è spazio per tutti" gave rise to several subsequent initiatives. The format we used was so successful, both in terms of the quality of the solutions and of the number of citizens involved, that we decided to use it as a model to be repeated. In October 2012, we organized a second version, where we proposed ten different design activities with the result of opening up the campus to more people. 
In 2013, the name and format changed due to a systemization through a Masters thesis in Product Service System Design ${ }^{1}$. In March there was the first "Il Sabato della Bovisa" (Bovisa Social Saturdays) to further underline the context of the Bovisa district, where it takes place. In that year the event became a monthly appointment for the campus by a regular involvement of the local associations to gather more people. The format was repeated for five months (from March to July 2013) with four main activities focusing on book sharing, children's games, gardening and light sports activities. It was then held twice in 2014 and in March 2015, where it was doubled (over two different days) and took place not only in the Bovisa campus but also in another hidden public space of the neighborhood (called Bovisasca).

\subsection{Discussion}

The main characteristics of this format are, first of all, the relationship between the campus and its neighborhood, and then the focus of the projects: all are toolkits designed by the students with and for a local association; and again, the temporary nature of the format. The success of these events can be seen by their numbers: from 250 visitors in the first edition in 2012 to 750 in March 2014. This underlines the results of making a hidden public space more visible to a larger number of people by using design actions.

This result is not only connected to the individual events but it also has a long-term application. One of the projects designed for the first event ( $C^{\prime}$ 'è giardino per tutti) was carried forward and became a permanent project: Coltivando - L'orto conviviale al Politecnico di Milano (Coltivando - The convivial garden at the Politecnico di Milano).

Coltivando was the result of a deep research on the urban agriculture topic within a public space and of a co-design process, lasting four months, which brought people back to the university campus more regularly by involving them in continuous activities (set-up, maintenance, etc.) in the garden. Coltivando was founded in October 2012 by a group of professors, researchers, and graduates of the Department of Design, and the School of Design of the Politecnico di Milano. Its main objective is, again, to connect two spatial and social entities that co-exist but do not connect with each other through conversation: the Durando university campus, established at the end of the 1990s, and the surrounding neighborhood of Bovisa. After more than two years, the garden is a thriving hub of community activity, and is considered a success. The team of organizers is made up of 15-20 participants from the neighborhood.

These two initiatives, a temporary event and a permanent community garden, generated awareness in the local neighborhood of the role of the campus and the university. But how could these projects become economically sustainable and/or adapted in other similar contexts?

This question is at the core of "campUS" - Incubation and Settings for Social Practices", a funded research project financed by the "Polisocial Award", a prize that awards social

\footnotetext{
${ }^{1}$ Roberta Motter, II Sabato della Bovisa, MSc Product Service System Design thesis, Politecnico di Milano, 2013
} 
innovation research projects within Politecnico di Milano. The project encompasses four different initiatives: the drawing up of guidelines for the design and the realization of urban community gardens, a neighborhood social TV network, a traveling pavilion to host the activities of the local associations; and the study of the economic sustainability of the three preceding initiatives. This research project is currently ongoing and underlines how the role of the designer as activator can enable people to live and use spaces on their own. The expected results at the end of the project (October 2016) will be a model of economic sustainability that will allow the outputs (community garden, social TV and traveling pavilion) to continue for a longer time.

Acknowledgements: We would like to thank the students, the associations and the local municipality who helped us to develop the outputs.

\section{References}

Anders, E. Hillgren, P. And Seravalli, A. (2011) Prototyping and Infrastructuring in design for social innovation. Co-Design Vol. 7, Nos. 3-4, September-December 2011, 169-183.

Barcellona, P., "Un convegno su arte e città" in Ferri, P., Fonti, D., Crescentini, M., (2006) lo arte - Noi città - natura e cultura dello spazio urbano, Gangemi Editore, Roma.

Björgvinsson, E., Ehn, P. And Hillgren, P. A. (2010, November). Participatory design and democratizing innovation. In Proceedings of the 11th Biennial Participatory Design Conference, Sydney, Australia. ACM, New York. 41-50.

Bugaric, B. "Active urban scenes" in Golicnik Marusic, B., Niksic, M., Courier, L., (edited by), (2010) Human Cities, Stitchting Kunstboek, Bruxelles.

Chatterton, P. (2000) The cultural role of universities in the community: revisiting the universitycommunity debate, Environment and Planning A, 32 (1): 165-181.

Careri, F. (2006) Walkscape, Einaudi.

Crespi, L. (2012) Da spazio nasce spazio, Postmedia books.

Fassi, D., (2012) Temporary Urban Solutions, Maggioli

Fassi, D., Meroni, A. and Simeone, G., Design for Social Innovation as a form of Design Activism: An action format. In Social Frontiers: The next edge of social innovation research conference proceedings, November, 14-15, 2013, NESTA, London. Acceded in February, 1, 2016 on the website: http://www.scribd.com/doc/191848489/Design-for-social-innovation-as-a-form-ofdesigning-activism-An-action-format.

Haydn, F., and Temel R., (2006) Temporary Urban Spaces: Concepts for the Use of City Spaces. Birkhäuser.

Hillmann, J. (2004) L'anima dei luoghi. Rizzoli.

Jacobs, J. (1961) The Death and Life of Great American Cities. Random House.

Manzini, E. (2015) Design when everybody design. MIT Press.

Meroni, A. (edited by), (2007) Creative Communities. Edizioni POLI.Design.

Motter R., (2013) I/ Sabato della Bovisa, MSc Product Service System Design thesis, Politecnico di Milano.

Navarra, M., (edited by), (2008) Repairing cities. LetteraVentidue edizioni. 
Ottavini, R. "Temporary/alternative use of the public space", in Centro de estudios AmbientAles, (2005) peripheries: inWArds, outWArds. documents of the 1st Convention "Landscape Urban Forum", VitoriA-Gasteiz.

Piccinno, G. (2008) Space Design. Maggioli.

Sennet, R. (1970) The Uses of Disorder: Personal Identity \& City Life, WWNorton.

Sassen, S. (2004) Le città nell'economia globale, il Mulino

Zajczyk, F. "Premessa" in Borlini, B., \& Memo ,F., (2008) I/ quartiere nella città contemporanea, Bruno Mondadori.

Zukin S., (1995) The Cultures of Cities, Blackwell.

About the Authors:

Davide Fassi, PhD, associate professor in Design at Politecnico di Milano and Tongji University. He belongs to the International Coordination Committee of DESIS Network - Design for Social innovation and sustainability. His research areas are urban agriculture and the connection between services and spaces

Laura Galluzzo, PhD in Design, Fellow Researcher and Contract Professor at the Politecnico di Milano. She has worked as a tutor on numerous workshops and studios in Interior and Service design at other international schools of design. In 2013 she co-founded MyHoming.

Liat Rogel, Phd in design from Politecnico di Milano. Product and service designer dealing with social and collaborative design. Founder of HousingLab, a laboratory for urban innovation in housing. She is currently teaching in NABA, Polidesign Master program and IES abroad Milan. 
"Over fifty years the Design Research Society has been fundamental to developing and supporting the field of Design Research. In that time many influential and innovative conferences have been held and the 50th Anniversary in Brighton conference continues that tradition. The breadth and depth of design research represented in these proceedings is extremely impressive and shows, I think, not only how important design research has become, but also the considerable potential that it holds for the future."

- Professor Nigel Cross PRESIDENT OF THE DRS

\section{0 次}

University of Brighton DesignResearchSociety

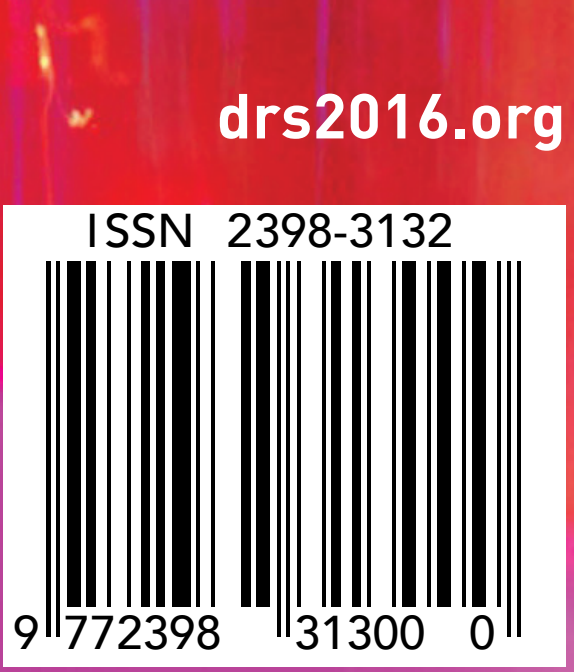

